\title{
Caspase-8 auto-cleavage regulates programmed cell death and collaborates with RIPK3/MLKL to prevent lymphopenia
}

\author{
Xiaoming $\mathrm{Li}^{1,6}$, Fang $\mathrm{Li}^{2,3,6}$, Xixi Zhang ${ }^{1}$, Haiwei Zhang ${ }^{1}$, Qun Zhao ${ }^{1}$, Ming $\mathrm{Li}^{1}$, Xiaoxia Wu${ }^{1}$, Lingxia Wang ${ }^{1}$, Jianling Liu ${ }^{1}$, Xuanhui Wu${ }^{1}$,
} Yangjing Ou ${ }^{1}$, Mingyan Xing ${ }^{1}$, Yue Zhang $\mathbb{D}^{4}{ }^{4}$, Jiangshan Deng ${ }^{5}$, Xiuzhe Wang ${ }^{5}$, Yan Luo ${ }^{4}$, Jinbao Li $\mathbb{D}^{2}$, Yuwu Zhao ${ }^{5}$ and Haibing Zhang (iD ${ }^{1}$

(c) The Author(s), under exclusive licence to ADMC Associazione Differenziamento e Morte Cellulare 2022

\begin{abstract}
Caspase-8 is an initiator of death receptor-induced apoptosis and an inhibitor of RIPK3-MLKL-dependent necroptosis. In addition, caspase- 8 has been implicated in diseases such as lymphoproliferation, immunodeficiency, and autoimmunity in humans. Although auto-cleavage is indispensable for caspase- 8 activation, its physiological functions remain poorly understood. Here, we generated a caspase-8 mutant lacking E385 in auto-cleavage site knock-in mouse (Casp $8^{\Delta E 385 / \Delta E 385}$ ). Casp $8^{\Delta E 385 / \Delta E 385}$ cells were expectedly resistant to Fas-induced apoptosis, however, Casp $8^{\triangle E 385 / \triangle E 385}$ cells could switch TNF-a-induced apoptosis to necroptosis by attenuating RIPK1 cleavage. More importantly, CASP8( $\triangle E 385)$ sensitized cells to RIPK3-MLKL-dependent necroptosis through promoting complex II formation and RIPK1-RIPK3 activation. Notably, Casp $8^{\triangle E 385 / \triangle E 385}$ Ripk $3^{-/-}$mice partially rescued the perinatal death of Ripk $1^{-1-}$ mice by blocking apoptosis and necroptosis. In contrast to the Casp $8^{-1-}$ Ripk $^{-1-}$ and Casp $8^{-1-} \mathrm{Mlkl}^{-1-}$ mice appearing autoimmune lymphoproliferative syndrome (ALPS), both Casp $8^{\Delta E 385 / \Delta E 385} \mathrm{Ripk3}^{-/-}$and $\operatorname{Casp~}^{\Delta E 385 / \Delta E 385} \mathrm{MI} / \mathrm{kl}^{-/-}$mice developed transplantable lymphopenia that could be significantly reversed by RIPK1 heterozygosity, but not by RIPK1 kinase dead mutation. Collectively, these results demonstrate previously unappreciated roles for caspase- 8 auto-cleavage in regulating necroptosis and maintaining lymphocytes homeostasis.
\end{abstract}

Cell Death \& Differentiation (2022) 29:1500-1512; https://doi.org/10.1038/s41418-022-00938-9

\section{INTRODUCTION}

Caspase-8 is a cysteinyl aspartate-specific protease that critically mediates extrinsic apoptosis [1-5] but also inhibits necroptosis [6-11]. In addition, caspase-8 is known to be crucially involved in the inflammatory response by acting as a scaffolding protein [12-16]. Previous studies demonstrated the death of Casp $8^{-1-}$ mice from RIPK3-MLKL mediated necroptosis $[9,10]$. This result highlights the critical role of the catalytic activity of caspase-8cFLIP complex in necroptosis inhibition [9]. In accordance with that, the conditional ablation of caspase- 8 in the intestinal epithelial cells or keratinocytes also leads to the inflammation and aberrant cell death in the intestine and skin, respectively [1721]. This can be prevented by the co-deletion of Ripk3 [17-21], indicating that caspase- 8 is required for tissue homeostasis by suppressing necroptosis. Moreover, mice expressing catalytically inactive RIPK3 D161N exhibit caspase-8-dependent embryonic lethality [22], suggesting that caspase-8 mediated apoptosis plays an essential role during embryonic development. In addition, caspase-8 phosphorylation mimic T265E knock-in mice were lately reported to be embryonically lethal [23], which indicated the phosphorylation of caspase-8 impaired the blockade of necroptosis during embryo development. Furthermore, caspase8-mediated apoptosis in association with caspase-11 and gasdermin-D-mediated epithelial cell death to regulate gut homeostasis and inflammation [20, 24]. Recent studies have demonstrated that deficiency of the enzymatic activity of CASP8 (C362S)/CASP8(C362A) not only promotes necroptosis but also triggers pyroptosis when necroptosis is inhibited in vivo $[6,8]$. The expression of catalytically inactive caspase-8 leads to embryonic lethality in mice that can be prevented by deletion of Ripk3 or coablation of Mlkl and Casp $1[6,8]$, suggesting that the enzymatic activity of caspase- 8 plays a critical role in the regulation of pyroptosis when apoptosis and necroptosis are compromised. In addition to the regulation of cell death, caspase- 8 contributes to the maintenance of immune homeostasis [11, 25-27]. When embryonic lethality in Casp8-deficient mice is rescued by Ripk3 or Mlkl ablation, the Casp8 ${ }^{-/-}$Ripk3 $^{-/-}$and Casp $8^{-/-} \mathrm{Mlkl}^{-/-}$mice develop lymphadenopathy [11] that resembles the abnormality observed in Fas ligand (FasL, CD95L) [28] or FAS [29, 30] deficient mice and human autoimmune lymphoproliferative syndrome (ALPS) [31, 32]. Casp8 ${ }^{\mathrm{C} 362 A / C 362 A}$ Ripk3 $^{-1-}$ mice also develop splenomegaly [8], indicating the potential of catalytic activity of

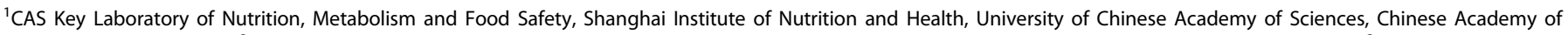

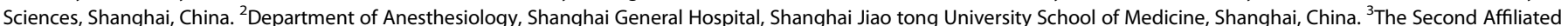

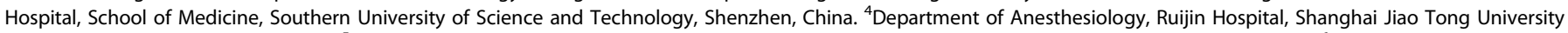

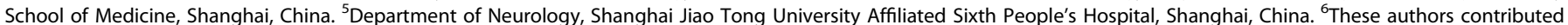
equally: Xiaoming Li, Fang Li. ${ }^{{ }}$email: hbzhang@sibs.ac.cn

Edited by J Silke

Received: 3 November 2020 Revised: 10 January 2022 Accepted: 11 January 2022

Published online: 21 January 2022 
caspase- 8 in immune homeostasis. Besides, caspase- 8 mutation in humans causes immunodeficiency [26] in addition to ALPS, which can be explained by the mechanisms that caspase- 8 cleaves and inactivates a cytokine production suppressor NEDD4-binding protein 1 (N4BP1) [33]. However, caspase-8 mutations in humans have also been linked to inflammatory bowel disease (IBD) [34] and multi-organ lymphocytic infiltration with granulomas [27], and the precise mechanisms underlying this relationship remain elusive.

On ligating with the death receptor, auto-cleavage leads to the activation of caspase-8 [35-40]. This initiates apoptosis, and in turn, inhibits necroptosis by cleaving critical necroptotic mediators such as CYLD [41], c-FLIP [42], RIPK1 [7, 43] and RIPK3 [44]. Furthermore, complete caspase- 8 activation requires dimerization and auto-cleavage of procaspase- 8 to unlock the enzymatic activity [35-37, 45]. The mice harboring mutation of caspase-8 auto-cleavage site at D387 developed normally and was impaired in extrinsic apoptosis in vivo [7, 13, 46, 47], and recent study showed that the non-cleavable caspase- 8 caused inflammation and induced ASC oligomerization in the lack of FADD [13]. However, the role of auto-cleavage of caspase- 8 in regulating necroptosis and cell death-independent function remains undefined.

Here, we generated knock-in mouse bearing caspase- 8 mutation lacking E385 in the auto-cleavage site (Casp $\left.8^{\triangle E 385 / \triangle E 385}\right)$ and found that caspase- 8 mutation $C A S P 8(\triangle E 385)$ not only switches TNF-a induced apoptosis to necroptosis by suppressing RIPK1 cleavage, but also unexpectedly promoted necroptosis through promoting complex II and RIPK1-RIPK3 activation. In addition, Casp $8^{\triangle E 385 / \triangle E 385} \mathrm{Ripk}^{-1-}$ and Casp $8^{\triangle E 385 / \triangle E 385} \mathrm{Mlkl}^{-/-}$mice developed lymphopenia with severe splenomegaly instead of the lymphoproliferative disease as observed in Casp ${ }^{-1-}$ Ripk $^{-/-}$and Casp ${ }^{-1-} \mathrm{Mlkl}^{-1-}$ mice. Collectively, these results suggest that caspase-8 auto-cleavage is not only required to mediate apoptosis but also inhibit necroptosis by negatively regulating complex II formation and stabilization and cooperates with RIPK3/MLKL maintaining lymphocytes homeostasis.

\section{RESULTS \\ Casp8 $8^{\Delta E 385 / \Delta E 385}$ mice are viable but develop a slight $\mathrm{CD8}^{+} \mathbf{T}$ cell lymphopenia in the spleen}

Previous studies have demonstrated that auto-cleavage of caspase-8 is required for mediating apoptosis but not for inhibiting necroptosis during development because the mice expressing none-cleavable Caspase- 8 are viable $[7,13,46]$. As expected, we observed that caspase- 8 cleavage was gradually enhanced when apoptosis was induced by tumor necrosis factor a (TNF-a) plus cycloheximide (CHX) in wild-type mouse dermal fibroblasts (MDFs) (Fig. 1A). Notably, caspase-8 cleavage was also increased in response to necroptotic stimulation with TNF-a plus Smac mimetics (Smac) and the pan-caspase inhibitor Z-VAD-FMK (zVAD). This finding was verified by observing the increased levels of phosphorylated RIPK1, RIPK3, and MLKL necroptotic markers (Fig. 1B). Therefore, in addition to its role in mediating apoptosis, caspase-8 cleavage is also hypothesized to regulate necroptosis.

Previous studies established transgenic mice expressing caspase-8 D387A [7, 13, 46], which cannot be cleaved between the large and small catalytic subunits. Caspase- 8 has a substrate preference for the tetrapeptide (Leu/Val)-Glu-X-Asp [48], which corresponds closely to the caspase- 8 auto-processing substrate sequence, L384/E385/V386/D387. We therefore hypothesized that E385 of caspase- 8 would also contribute to its auto-cleavage. To explore the contribution of caspase-8 (E385) in its auto-processing in vitro and in vivo, we generated a knock-in mouse that expressed caspase-8 lacking E385 in the auto-cleavage site between the large and small catalytic subunits (Fig. S1A). In contrast to the embryonic lethality observed in caspase- 8 deficiency [49] and catalytically inactive caspase-8 mice [6, 8], Casp $8^{\triangle E 385 / \triangle E 385}$ mice were viable and matured normally (Fig. S1B), which was consistent with previously reported mouse lines expressing caspase-8(D387A) $[7,13,46]$. To test whether CASP8 $(\triangle \mathrm{E} 385)$ is indeed unable to auto-process between the large and small catalytic subunits, we treated primary WT and Casp $8^{\triangle E 385 /}$ $\triangle E 385$ BMDMs with LPS/BV6 to induce apoptosis. Compared with the dramatic caspase- 8 cleavage in wild-type BMDMs, caspase- 8 cleavage between the large and small catalytic subunits was confirmed to be blocked in Casp $8^{\triangle E 385 / \triangle E 385}$ BMDMs utilizing two different antibodies (Fig. S1C). Besides, it was observed that the expression of CASP8( $\triangle E 385)$ in multiple tissues including spleen, lung, liver, kidney, colon, heart, ileum, and rectum was normal in Casp $8^{\triangle E 385 / \triangle E 385}$ mice (Fig. 1C and S1D), suggesting that the cleavage of caspase- 8 is dispensable for its expression and stability in vivo. Next, we examined the effect of CASP8( $\Delta E 385)$ on the pathologies. Histopathological examination demonstrated that the appearance of multiple tissues was indistinguishable in Casp $8^{\triangle E 385 / \triangle E 385}$ mice in comparison with the tissue appearance in WT mice (Fig. S1E). However, we observed that the Casp $8^{\triangle E 385 /}$ $\triangle E 385$ mice developed slight splenomegaly with a mild decrease in the percentage of the $\mathrm{CD} 8^{+}$T cells in the spleen and bone marrow (Fig. 1D-F). However, no differences were observed between Casp $8^{\triangle E 385 / \triangle E 385}$ and WT mice with respect to the B cells and the myeloid cell subsets obtained from the spleen, lymph nodes, and bone marrow (Fig. 1F). These results show that the Casp $8^{\triangle E 385 / \triangle E 385}$ mice are viable but develop a slight $\mathrm{CD}^{+} \mathrm{T}$ cell lymphopenia with splenomegaly.

\section{Apoptosis induced by TNF-a was switched to necroptosis by attenuating RIPK1 cleavage in Casp $8^{\triangle E 385 / \triangle E 385}$ cells}

Previous studies have demonstrated that the auto-cleavage of caspase- 8 is essential for the apoptosis induced by the anti-Fas antibody Jo2, in vitro $[7,13,46]$ and in vivo $[13,46]$. Consistently, we observed that the thymocyte apoptosis induced by anti-Fas from Casp $8^{\triangle E 385 / \triangle E 385}$ mice was compromised compared to that from WT mice (Fig. S2A), and anti-Fas antibody also induced less caspase-3 cleavage in Casp $8^{\triangle E 385 / \triangle E 385}$ thymocytes (Fig. 2A). To further investigate the role of caspase-8 cleavage in apoptosis, we treated Casp $8^{\triangle E 385 / \triangle E 385}$ MDFs with a RIPK3 kinase inhibitor, GSK'872, to induce apoptosis [50]. We observed that Casp $8^{\triangle E 385}$ ' $\triangle E 385$ MDFs were strongly resistant to apoptosis induced by GSK'872 (Fig. 2B). This finding was confirmed by attenuating the cleavage of caspase-3 in Casp $8^{\triangle E 385 / \triangle E 385}$ MDFs (Fig. 2C). To further verify the contribution of caspase- 8 cleavage in apoptosis in vivo, we challenged the anti-Fas antibody, Jo2, by intravenous injection in $\operatorname{Casp} 8^{\triangle E 385 / \triangle E 385}$ and WT mice. In accordance with previous studies $[13,46], \operatorname{Casp}^{\triangle E 385 / \Delta E 385}$ mice were significantly protected from the Jo2-induced lethal effects compared to WT mice (Fig. 2D). Accordingly, Casp $8^{\triangle E 385 / \triangle E 385}$ mice exhibited alleviated liver damage and decreased alanine aminotransferase (ALT)/aspartate aminotransferase (AST) concentrations in the plasma compared to the liver function in WT control mice (Fig. 2E and S2B). In line with these data, we observed the absence of caspase- 8 cleavage and a significant decrease in caspase- 3 cleavage in the livers of Casp $8^{\triangle E 385 / \triangle E 385}$ mice (Fig. S2C), suggesting that the lethal effects exerted by the anti-Fas antibody Jo2-induced apoptosis were decreased in $C a s p 8^{\Delta E 385 / \triangle E 385}$ mice in vivo. These results suggested that blocking cleavage between the large and small catalytic subunits by $\mathrm{CASP} 8(\triangle \mathrm{E} 385)$ is enough to prevent apoptosis in vitro and in vivo.

To further investigate whether CASP8 $(\triangle \mathrm{E} 385)$ is required for TNF-a-induced apoptosis, we treated the Casp $8^{\triangle E 385 / \triangle E 385}$ MDFs with TNF-a plus Smac. In contrast to the WT MDFs showing increased caspase-8 cleavage, Casp $8^{\triangle E 385 / \triangle E 385}$ MDFs showed no detectable caspase- 8 auto-cleavage between the large and small catalytic subunits (Fig. S3A). However, in contrast with the previous findings that the apoptosis induced by GSK' 872 
A

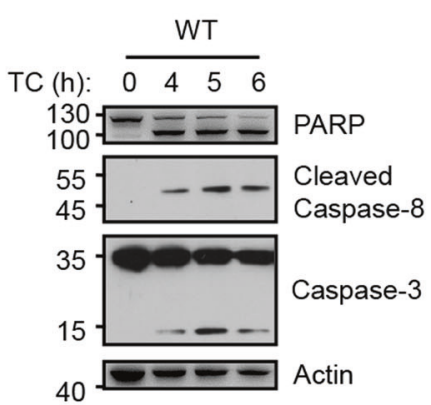

B

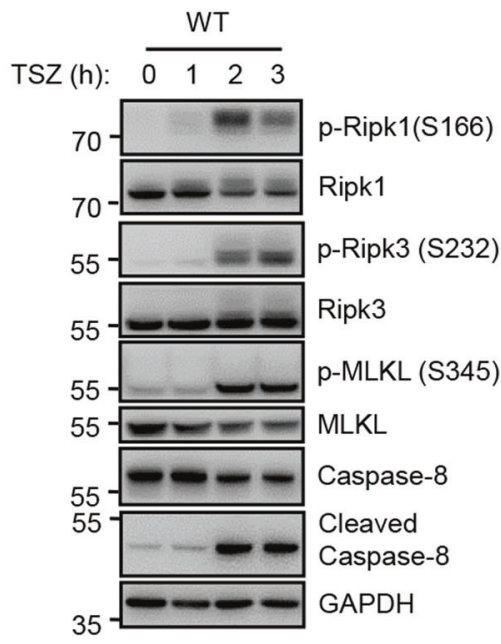

C
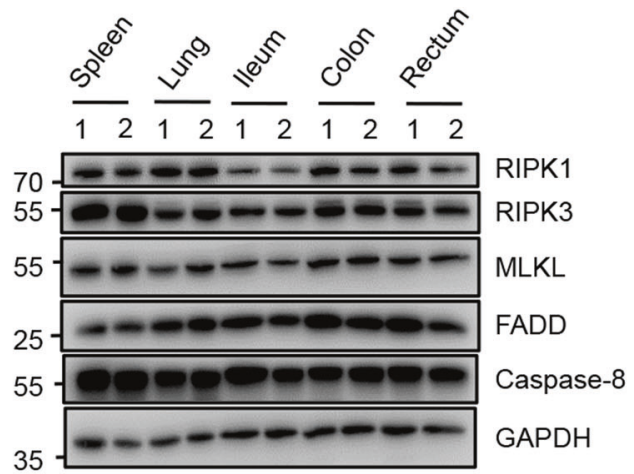

D

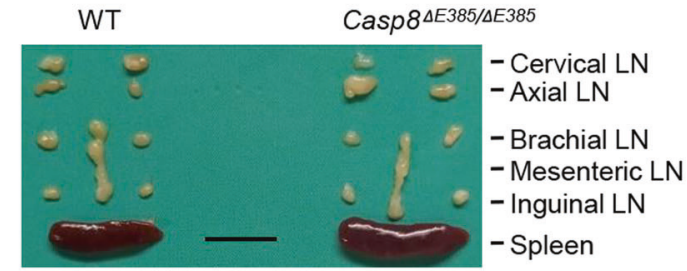

E

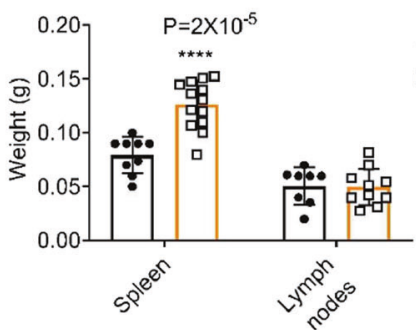

F

Spleen

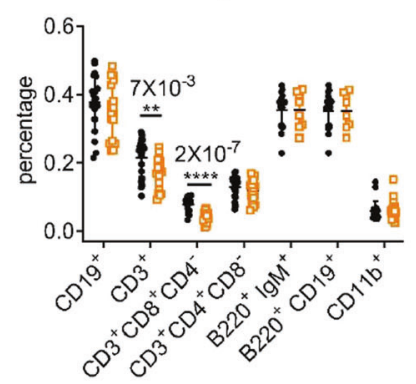

Lymph nodes

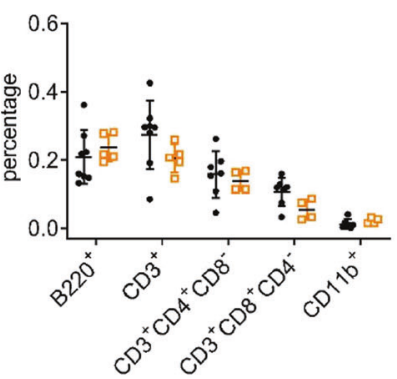

Bone Marrow

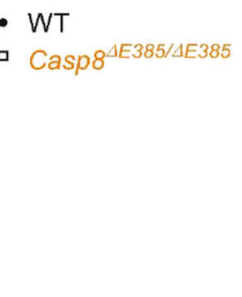

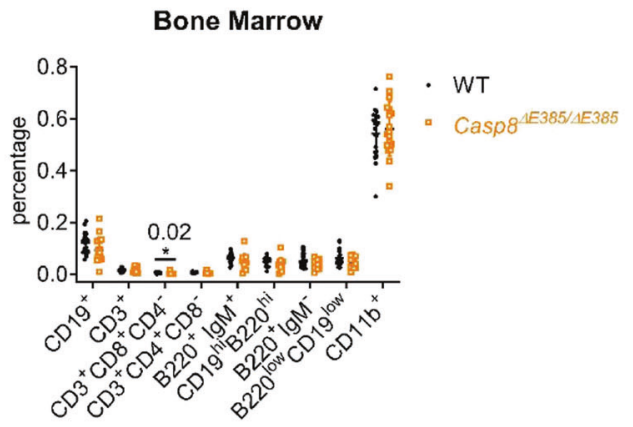

Fig. 1 Casp $8^{\Delta E 385 / \Delta E 385}$ mice are viable and develop a slight lymphopenia. A Western blot of primary wild-type (WT) MDFs which were treated with TNF- $\alpha(40 \mathrm{ng} / \mathrm{ml})+$ Cycloheximide $(\mathrm{CHX})(40 \mu \mathrm{g} / \mathrm{ml})(\mathrm{TC})$ for the indicated time. B Western blot of primary WT MDFs which were treated with TNF- $\alpha(20 \mathrm{ng} / \mathrm{ml})+$ Smac mimetic (Smac) $(1 \mu \mathrm{M})+\mathrm{zVAD}(20 \mu \mathrm{M})(\mathrm{TSZ})$. C Western blot of RIPK1, RIPK3, MLKL, FADD, caspase-8, and GAPDH in the indicated organs of WT (1) and Casp8 ${ }^{\triangle E 385 / \triangle E 385}$ (2) mice. D Lymph nodes and spleens removed from 16-week old mice of indicated genotypes (scale bar, $1 \mathrm{~cm}$ ). E Dot plot of weight of lymph nodes (parts showed in Fig. 1D) and spleens of 12- to 16-week old WT, Casp $8^{\triangle E 385 / \triangle E 385}$ mice. Bars, mean \pm SD. $P$ values above the asterisk (unpaired, two-tailed $t$ test) ${ }^{* * * *} p<0.0001$, compared to the WT mice. F Different cell subsets from spleen, lymph nodes (parts showed in Fig. 1D) and bone marrow of 12- to 16-week old WT and Casp8 ${ }^{\triangle E 385 / \triangle E 385}$ mice were analyzed by flow cytometry using the following markers: $B$ cells $\left(B 220^{+}\right.$or $\left.\mathrm{CD} 19^{+}\right), \mathrm{T}_{\text {cells }}\left(\mathrm{CD} 3^{+}\right), \mathrm{CD}^{+}{ }^{+} \mathrm{T}_{\mathrm{cells}}\left(\mathrm{CD} 3^{+} \mathrm{CD} 4^{+} \mathrm{CD} 8^{-}\right)$,

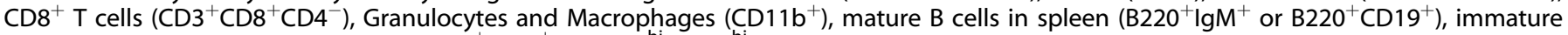
and mature $B$ cells in bone marrow $\left(B 220^{+} \operatorname{lgM}^{+}\right.$or $B 220^{\text {hi }} C D 19^{\text {hi }}$ ), progenitor $B$ cells (pro-B) and precursor $B$ cells (pre-B) in bone marrow $\left(\mathrm{B}_{220^{+}} \mathrm{IgM}^{-}\right.$or $\left.\mathrm{B} 220^{\text {low }} \mathrm{CD} 19^{\text {low }}\right)$. Bars, mean $\pm \mathrm{SD}$. $P$ values above the asterisk (unpaired, two-tailed $t$ test) ${ }^{*} p<0.05,{ }^{* *} p<0.05,{ }^{* * *} p<0.0001$.

decreased in Casp $8^{\Delta E 385 / \triangle E 385}$ MDFs, we observed that increased cell death in Casp $8^{\triangle E 385 / \triangle E 385}$ MDFs upon stimulation with TNF-a plus Smac/CHX compared to the death in WT MDFs (Fig. 2F). Interestingly, we further observed that caspase-3 cleavage induced by TNF-a plus Smac in WT MDFs was decreased in Casp $8^{\triangle E 385 / \triangle E 385}$ MDFs (Fig. S3A). Given that the necroptosis suppression function of caspase-8 [51], we speculated that CASP8( $\triangle \mathrm{E} 385)$ could switch apoptosis to necroptosis under certain conditions. Therefore, we measured the markers of cell death pathways in MDFs in response to the stimulation by TNF-a/CHX and TNF-a/Smac. The Casp $8^{\triangle E 385 / \triangle E 385}$ MDFs showed upregulation in RIPK1, RIPK3, and MLKL 
A

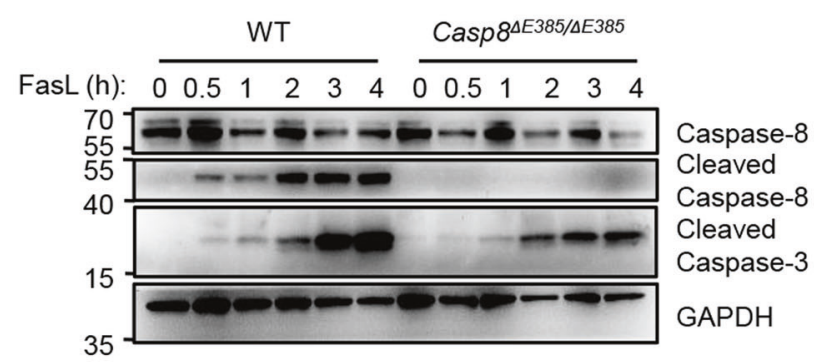

B

MDFS

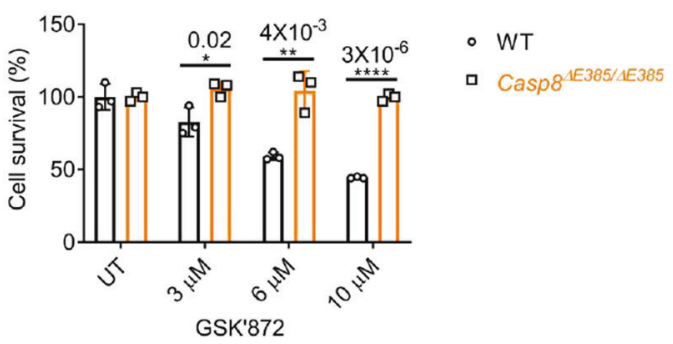

C

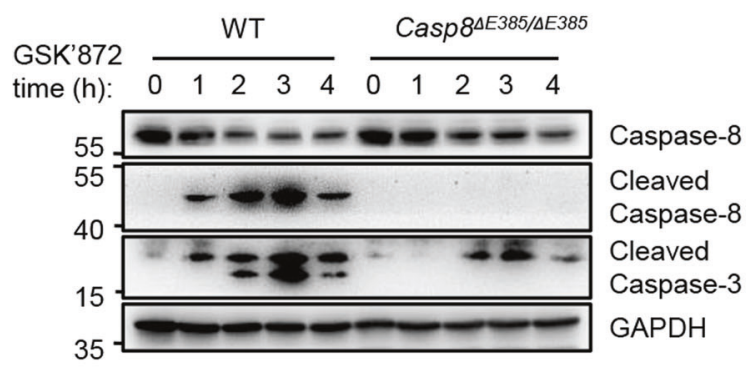

$\mathbf{F}$

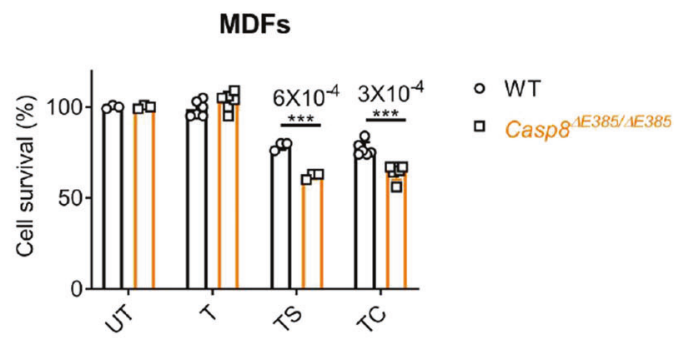

phosphorylation but a decrease in RIPK1 and caspase-3 cleavage (Fig. $2 \mathrm{G}$ and $\mathrm{S} 3 \mathrm{~A}$ ). This indicates that the CASP8 $(\triangle \mathrm{E} 385)$ switched TNF-a/CHX and TNF- $\mathrm{a} / \mathrm{Smac}$ induced caspase3-dependent apoptosis to RIPK1-RIPK3-MLKL-mediated necroptosis owing to the attenuation of RIPK1 cleavage. Collectively,
D

Anti-Fas i.v.

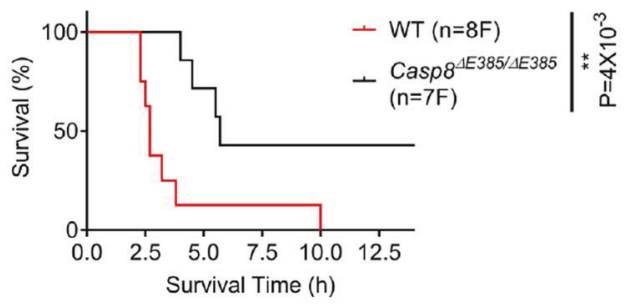

E

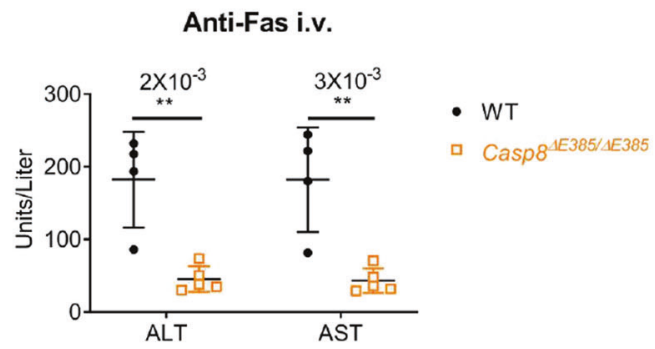

G

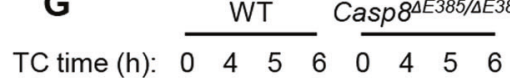

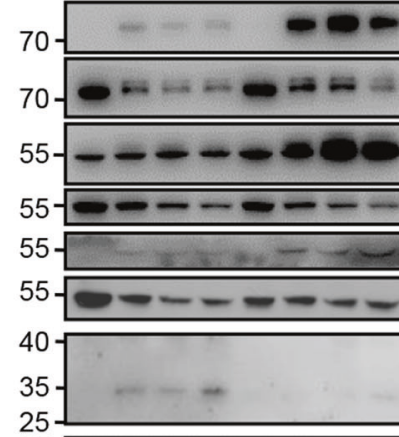

p-RIPK1 (S166)

RIPK1

p-RIPK3 (S232)

RIPK3

p-MLKL (S345)

MLKL

Cleaved RIPK1

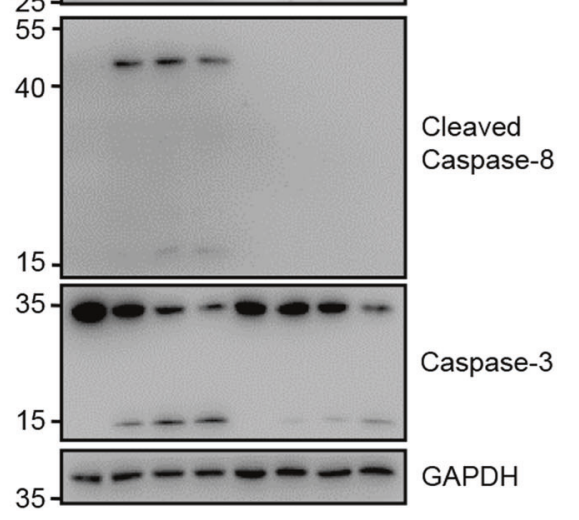

these results demonstrate that caspase- 8 cleavage between the large and small catalytic subunits is required for mediating apoptosis, but CASP8( $\triangle E 385)$ promotes cell death switch from apoptosis to RIPK1-RIPK3-MLKL-dependent necroptosis under certain conditions. 
Fig. 2 The CASP8( $\triangle E$ E385) compromises apoptosis, particularly switches TNF-a induced apoptosis to necroptosis. A Western blotting analysis of the indicated protein in primary WT and Casp $8^{\triangle E 385 / \triangle E 385}$ thymocytes which were treated with FasL (Jo-2) $(1 \mu \mathrm{g} / \mathrm{ml})$ for the indicated time. The data are representative of three independent experiments. B Primary WT and Casp $8^{\triangle E 385 / \triangle E 385}$ MDFs were treated with GSK' 872 in different concentration for the indicated time respectively. Bars, mean \pm SD. $P$ values above the asterisk (unpaired, two-tailed $t$ test) ${ }^{*} p<0.05$, ${ }^{* *} p<0.01,{ }^{* * *} p<0.0001$. C Western blotting analysis of protein expression of caspase-8, cleaved caspase-8, cleaved caspase-3 and GAPDH in primary WT and Casp $8^{\Delta E 385 / \triangle E 385}$ MDFs which were treated with GSK'872 $(20 \mu \mathrm{M})$ for the indicated time. D Mouse survival curve of 8 - to 12 week old mice after challenged by anti-Fas antibody (Jo-2, $0.5 \mu \mathrm{g} / \mathrm{g}$, i.v.). F, female. $P$ values alongside the asterisk, two-sided Log-rank (MantelCox) test, ${ }^{* *} p<0.01$. E The alanine transaminase (ALT) and aspartate transaminase (AST) levels in serum of the 16-week old WT, Casp $8^{\Delta E 385 / \triangle E 385}$ mice $2.5 \mathrm{~h}$ after anti-Fas injection. Bars, mean $\pm \mathrm{SD}$. $P$ values above the asterisk (unpaired, two-tailed $t$ test), ${ }^{* *} p<0.01$. F Primary WT and Casp $8^{\triangle E 385 / \triangle E 385}$ MDFs were treated with TNF- $\alpha(20 \mathrm{ng} / \mathrm{ml})$, TNF- $\alpha+$ Smac $(1 \mu \mathrm{M})(\mathrm{TS})$, TNF- $\alpha+$ CHX $(20 \mu \mathrm{g} / \mathrm{ml})(\mathrm{TC})$ for $5 \mathrm{~h}$. Bars, mean \pm SD. $P$ values above the asterisk (unpaired, two-tailed $t$ test) ${ }^{* * *} p<0.001$. G Immunoblotting of the indicated protein expression in primary WT and Casp $8^{\triangle E 385 / \triangle E 385}$ MDFs which were treated with TNF- $\alpha(40 \mathrm{ng} / \mathrm{ml})+\mathrm{CHX}(40 \mu \mathrm{g} / \mathrm{ml})$ (TC) for the indicated time.

CASP8(DE385) promotes necroptosis upon various necroptotic stimuli both in vitro and in vivo

Caspase-8 suppresses RIPK3-MLKL mediated necroptosis [9-11], and caspase- 8 catalytic activity is essential for inhibiting necroptosis during development, as demonstrated recently $[6,8]$. To investigate the role of caspase- 8 auto-cleavage in necroptosis regulation, we induced necroptosis in MDFs via TNF-a plus Smac and $z V A D$ and in bone marrow-derived macrophages (BMDMs) via stimulation with LPS or poly(l:C) plus zVAD. Notably, we observed that Casp $8^{\triangle E 385 / \triangle E 385}$ MDFs and BMDMs showed excessive cell death compared to their WT counterparts, which could also be rescued by Nec-1 (Figs. 3A, B). RIPK1 [7], RIPK3 [52-54] and MLKL $[55,56]$ are the main executors of programmed necroptosis via cascade phosphorylation. To further investigate the mechanism by which caspase-8 cleavage regulates necroptosis, we first examined RIPK1-RIPK3-MLKL axis signaling. Indeed, compared with the WT MDFs, the Casp $8^{\triangle E 385 / \triangle E 385}$ MDFs showed significant increase in the phosphorylation of RIPK1, RIPK3, and MLKL and oligomerization of MLKL after TNF-a plus Smac/CHX and ZVAD stimulation (Figs. 3C, D, and S3B). Similar results were observed in Casp $8^{\triangle E 385 / \triangle E 385}$ BMDMs in LPS plus zVAD-induced necroptosis (Fig. S3C).

As the pan-caspase inhibitor Z-VAD-FMK blocked the caspase-8 enzymatic activity both in wild-type and Casp $8^{\triangle E 385 / \triangle E 385}$ cells, we wondered why Casp $8^{\triangle E 385 / \triangle E 385}$ cells still showed excessive necroptosis compared with WT cells in the presence of zVAD. Previous study demonstrated that TNF-a induced cell death depends on complex II, which contains RIPK1, FADD, caspase-8, RIPK3 and MLKL [52-54, 57-61]. Regulated by several proand anti-apoptotic and pro- and anti-necroptotic proteins [6-8, 41, 43, 44, 62-64], complex-II can trigger apoptosis or necroptosis. Thus, we analyzed whether complex II was enhanced in Casp $8^{\triangle E 385 / \triangle E 385}$ MDFs under necroptotic stimulation. When MDFs were stimulated by TNF- $\mathrm{a} / \mathrm{CHX} / \mathrm{zVAD}$, we found obviously sustained and enhanced interaction of RIPK3 and FADD with RIPK1 in Casp $8^{\triangle E 385 / \triangle E 385}$ MDFs than in wild-type cells (Fig. 3E). Furthermore, we detected dramatically increased p-Ser166 RIPK1 and $\mathrm{p}$-Ser232 RIPK3 within complex II in TNFa/CHX/zVAD treated Casp $8^{\triangle E 385 / \triangle E 385}$ MDFs compared to WT MDFs (Fig. 3E). Besides, we also found enhanced complex II assembly in Casp $8^{\Delta E 385 / \triangle E 385}$ BMDMs under LPS/zVAD treatment (Fig. 3F).

As ZVAD itself can promote complex II formation, we wondered whether Casp $8^{\triangle E 385 / \triangle E 385}$ cells still showed enhanced complex II assembly in the absence of zVAD. Thus, we stimulated wild-type and Casp $8^{\triangle E 385 / \triangle E 385}$ MDFs with TNF-a/CHX. We found that TNF-a/ $\mathrm{CHX}$ treatment can still induce increased interaction of caspase-8, FADD and RIPK3 with RIPK1 in Casp $8^{\triangle E 385 / \triangle E 385}$ cells instead of the WT cells (Fig. 3G), suggesting that caspase-8 cleavage can negatively regulated complex II assembly. Besides, we also found increased phosphorylation of RIPK1, RIPK3 and decreased caspase3 cleavage in TNF-a/CHX treated $\operatorname{Casp} 8^{\Delta E 385 / \triangle E 385}$ MDFs, which also indicated that CASP8( $\triangle \mathrm{E} 385)$ switched TNF-a/CHX induced apoptosis to necroptosis (Fig. 3G). Prior evidence showed that stimulation of the Toll-like receptor (TLR) and an IAP inhibitor, can also trigger complex II assembly $[15,65,66]$. Thus, we treated BMDMs with TLR4 agonist LPS plus BV6 to induce complex II formation. Consistently, LPS/BV6 treatment also induced markedly enhanced complex II formation in Casp $8^{\triangle E 385 / \triangle E 385}$ BMDMs compared with WT counterpart (Fig. S3D). Collectively, these results demonstrate that $C A S P 8(\triangle E 385)$ functions as a scaffold to promote complex II formation in order that the recruitment of RIPK3-caspase-8-FADD and RIPK1-RIPK3 cascade phosphorylation were significantly increased and prolonged, which results in excess necroptosis in Casp $8^{\triangle E 385 / \triangle E 385}$ cells. In addition, TNF-ainduced lethal systemic inflammatory syndrome has been wildly recognized as a mouse model to confirm necroptosis in vivo $[7,23]$. Therefore, we tested whether CASP8( $\triangle \mathrm{E} 385)$ affects the lethal SIRS model in Casp $8^{\triangle E 385 / \triangle E 385}$ mice. In comparison to WT, Casp $8^{\triangle E 385 / \triangle E 385}$ mice showed significantly sensitized death accompanied by severe hypothermia (Figs. 4A, B). Furthermore, Ripk $3^{-/-}$Casp $8^{\Delta E 385 / \triangle E 385}$ and Ripk $1^{K 45 A / K 45 A}$ Casp $8^{\triangle E 385 / \triangle E 385}$ mice were protected to a large extent from the lethal shock (Figs. 4A, B). Moreover, to examine whether caspase- 8 cleavage suppresses necroptosis in macrophages in vivo, WT, Casp $8^{\triangle E 385 / \triangle E 385}$ and Ripk $1^{+/-}$Ripk $^{-/-}$Casp $8^{\Delta E 385 / \triangle E 385}$ mice were pretreated with zVAD followed by challenging with LPS administration. After $24 \mathrm{~h}$, the $\mathrm{CD} 11 \mathrm{~b}^{+} \mathrm{F} 4 / 80^{+}$intraperitoneal macrophages (PMs) were detected by flow cytometry. The $\mathrm{CD} 11 \mathrm{~b}^{+} \mathrm{F} 4 / 80^{+} \mathrm{PMs}$ harvested from Casp $8^{\triangle E 385 / \triangle E 385}$ mice were dramatically decreased compared to those observed in WT mice after the LPS plus ZVAD treatment, and the excessive peripheral macrophages loss in Casp $8^{\Delta E 385 / \Delta E 385}$ mice was largely protected in Ripk $1^{+/-}$Ripk $^{-/-}$Casp $^{\Delta E 385 / \Delta E 385}$ mice (Figs. 4C, D). Collectively, these data reveal that caspase- 8 cleavage is essential for suppressing RIPK1-RIPK3-MLKL-mediated necroptotic death in vitro and in vivo.

\section{Casp $8^{\Delta E 385 / \Delta E 385}$ Ripk3 $^{-/-}$mice develop serious lymphopenia and myeloid bias but prevent postnatal lethality in Ripk ${ }^{-/-}$ mice}

Casp8 ${ }^{-/-}$Ripk3 $^{-1-}$ and Casp $8^{-/-} \mathrm{Mlkl}^{-1-}$ mice [11], characterized by splenomegaly with a marked accumulation of $\mathrm{CD} 3^{+} \mathrm{CD} 4^{-} \mathrm{CD} 8^{-} \mathrm{B} 220^{+}$ T cells, resemble the deficiency of FAS ligand (FasL, CD95L) [28] or FAS (CD95) $[29,30]$ in mice or the autoimmune lymphoproliferative syndrome (ALPS) in humans [31]. To investigate the role of caspase-8 auto-cleavage in this disease, we generated Casp $8^{\triangle E 385 / \triangle E 385}$ Ripk $^{-/-}$ and Casp $8^{\triangle E 385 / \Delta E 385} \mathrm{Mlkl}^{-1-}$ mice by crossing Casp $8^{\triangle E 385 / \triangle E 385}$ mice to Ripk3 $^{-1-}$ or $\mathrm{Mlkl}^{-1-}$ background. Remarkably, Casp $8^{\triangle E 385 / \Delta E 385} \mathrm{Ripk}^{-/-}$ and Casp $8^{\triangle E 385 / \triangle E 385} \mathrm{Mlkl}^{-1-}$ mice develop severe lymphopenia characterized by fewer lymphocytes in multiple organs (Figs. 5B, D, and S4A, B). Although Casp $8^{\triangle E 385 / \triangle E 385}$ mice developed slight splenomegaly and $\mathrm{CD}^{+} \mathrm{T}$ cell lymphopenia in the spleen, Casp $8^{\triangle E 385 / \Delta E 385} \mathrm{Ripk}^{-1-}$ and Casp ${ }^{\triangle E 385 / \Delta E 385} \mathrm{Mlkl}^{-1-}$ mice developed more severe splenomegaly and showed a dramatically decreased percentage of $B$ cells $\left(C D 19^{+}\right)$and $T$ cells $\left(C D 3^{+}\right)$as well as an increased percentage of myeloid-derived cells $\left(C D 11 b^{+}\right)$in the spleen and bone marrow (Fig. 5A, and S4A, B). This result indicates the possibility of lymphopenia and myeloid bias/myeloproliferative disease in these mice. Next, we counted the absolute cell number 
A

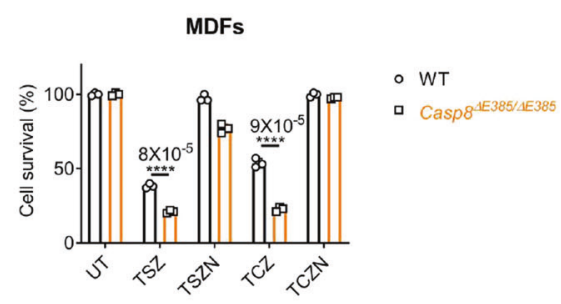

B

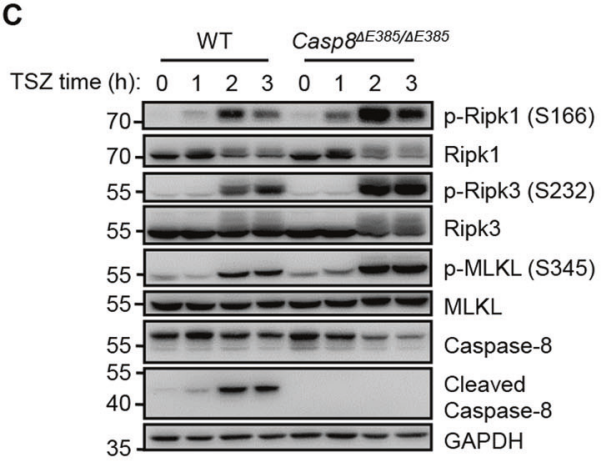

D

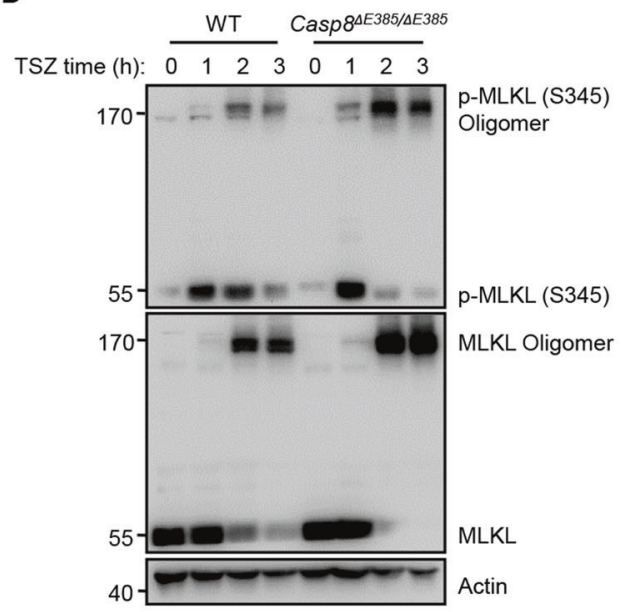

E

TCZ time (h): $\quad \frac{\text { WT }}{022.252 .5} \frac{\operatorname{Casp8} 8^{\Delta E 385 / \Delta E 385}}{022.252 .5}$

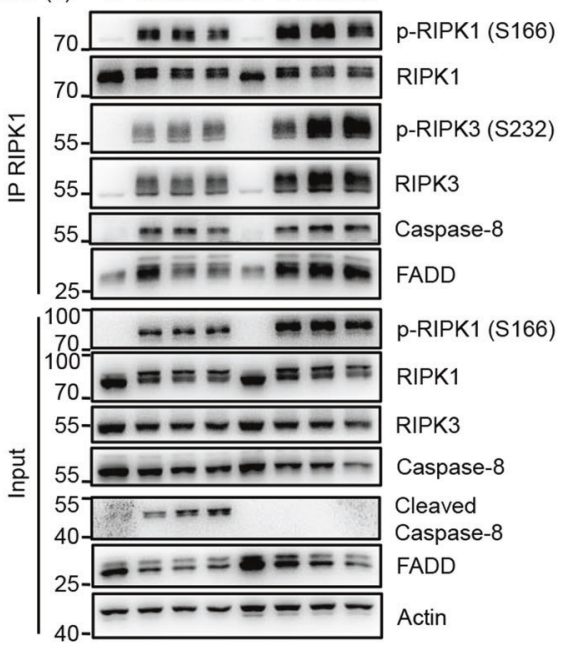

$\mathbf{F}$

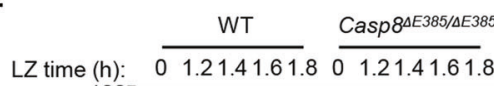

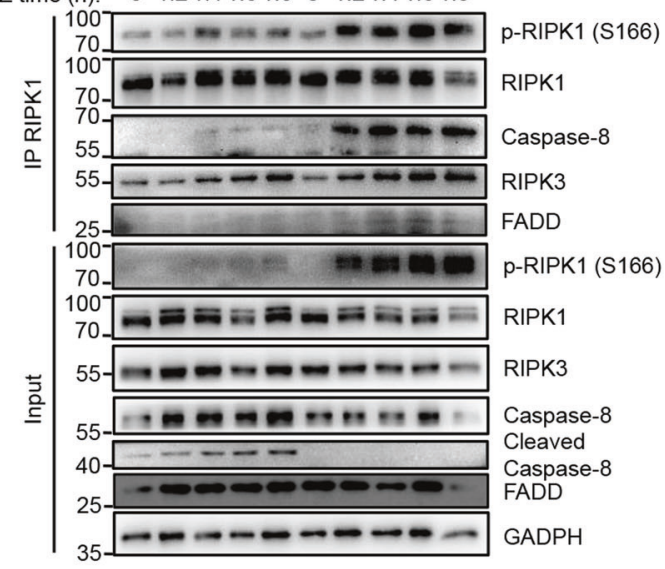

G

WT Casp8 $8^{\Delta E 385 / \triangle E 385}$

TC time (h): $\quad 0 \quad 2.53 .50 \frac{2.53 .5}{0}$

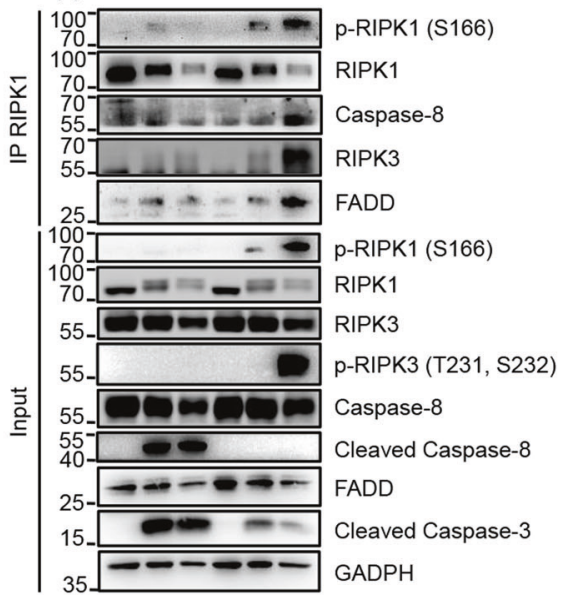

excluded the possibility of myeloproliferative disease in these mice. Furthermore, we analyzed the subsets of B cells and T cells in the spleen and bone marrow. Consistent with the percentage results (Fig. S4C), immature and mature $B$ cells $\left(B 220^{+} \operatorname{lgM}^{+} / B 220^{\text {hi }} C D 19^{\text {hi }}\right)$, progenitor $B$ cells (pro-B) and precursor $B$ cells (pre-B) $\left(B 220^{+}\right.$ 
Fig. 3 The CASP8( $\triangle$ E385) promotes necroptosis in vitro. A Primary WT and Casp $8^{\triangle E 385 / \triangle E 385} \mathrm{MDFs}$ were treated with TNF- $\alpha(20 \mathrm{ng} / \mathrm{ml})+\mathrm{Smac}$ $(1 \mu \mathrm{M})+\mathrm{zVAD}(20 \mu \mathrm{M})(\mathrm{TSZ})$ and TNF- $\alpha+$ Smac + zVAD + Nec-1 $(30 \mu \mathrm{M})(\mathrm{TSZN})$ for $6.45 \mathrm{~h}, \mathrm{TNF}-\alpha+\mathrm{CHX}(20 \mu \mathrm{g} / \mathrm{ml})+\mathrm{zVAD}(20 \mu \mathrm{M})(\mathrm{TCZ})$ and TNF- $\alpha+\mathrm{CHX}+\mathrm{zVAD}+\mathrm{Nec}-1(30 \mu \mathrm{M})(\mathrm{TCZN})$ for $4.45 \mathrm{~h}$. Bars, mean $\pm \mathrm{SD}$. $P$ values above the asterisk (unpaired, two-tailed $t$ test) ${ }^{* * * *} p<0.0001$. B Primary WT and Casp $8^{\triangle E 385 / \triangle E 385}$ bone marrow derived macrophages (BMDMs) were treated with LPS (100 ng/ml), LPS + zVAD (20 $\mu$ M) (LZ), LPS + zVAD + Nec-1 $(30 \mu \mathrm{M})(\mathrm{LZN})$, poly(l:C) $(100 \mu \mathrm{g} / \mathrm{ml})$, poly $(\mathrm{l}: \mathrm{C})+\mathrm{zVAD}(20 \mu \mathrm{M})(\mathrm{PZ})$, poly(l:C) + zVAD + Nec-1 $(30 \mu \mathrm{M})(\mathrm{PZN}), \mathrm{TNF}-\alpha+\mathrm{Smac}$ + zVAD (TSZ), TNF- $\alpha+$ Smac + zVAD + Nec-1 (TSZN) for $3 \mathrm{~h}$. Bars, mean \pm SD. $P$ values above the asterisk (unpaired, two-tailed $t$ test) ${ }^{* * *} p<$ $0.001,{ }^{* * * *} p<0.0001$. C Immunoblotting of the indicated protein expression in primary WT and Casp $8^{\triangle E 385 / \triangle E 385}$ MDFs which were treated with TNF- $\alpha(20 \mathrm{ng} / \mathrm{ml})+$ Smac $(1 \mu \mathrm{M})+\mathrm{zVAD}(20 \mu \mathrm{M})$ (TSZ) for the indicated time. D Immunoblotting of primary WT and Casp $8^{\Delta E 385 / \triangle E 385} \mathrm{MDFs}$ which were treated with TNF- $\alpha(20 \mathrm{ng} / \mathrm{ml})+$ Smac $(1 \mu \mathrm{M})+\mathrm{zVAD}(20 \mu \mathrm{M})(\mathrm{TSZ})$ for the indicated time. E WT and Casp $8^{\Delta E 385 / \triangle E 385} \mathrm{MDFs}$ were treated with TNF- $\alpha(40 \mathrm{ng} / \mathrm{ml})+\mathrm{CHX}(40 \mu \mathrm{g} / \mathrm{ml})+\mathrm{zVAD}(50 \mu \mathrm{M})$ for the indicated time, complex II was immunoprecipitated using anti-RIPK1, the recruitment of RIPK3, FADD and caspase-8 were detected by western blotting. F Primary WT and Casp $8^{\triangle E 385 / \triangle E 385}$ BMDMs were treated with LPS $(200 \mathrm{ng} / \mathrm{ml})+\mathrm{zVAD}(40 \mu \mathrm{M})$ followed by western blot and immunoprecipitation. G Primary WT and Casp $8^{\Delta E 385 / \Delta E 385} \mathrm{MDFs}$ were treated with TNF- $\alpha(40 \mathrm{ng} / \mathrm{ml})+\mathrm{CHX}(40 \mu \mathrm{g} / \mathrm{ml})$ followed by western blot and immunoprecipitation.

$\left.\operatorname{lgM}^{-} / \mathrm{B}_{220}{ }^{\text {low }} \mathrm{CD} 19^{\text {low }}\right)$, and $\mathrm{CD} 8^{+} \mathrm{T}$ cells showed a dramatic decrease in the bone marrow of $\operatorname{Casp} 8^{\Delta E 385 / \triangle E 385}$ Ripk $^{-1-}$ and Casp $8^{\triangle E 385 /}$ ${ }_{\triangle E 385} \mathrm{Mlkl}^{-1-}$ mice (Fig. 5C and S4D). In the spleen, the absolute cell numbers of peripheral $B$ cells and T cells were also decreased (Fig. 5C). Taken together, these data showed that the Casp $8^{\triangle E 385 / \triangle E 385}$ Ripk $^{-/}$ and $\operatorname{Casp}^{\Delta E 385 / \triangle E 385} \mathrm{MlkJ}^{-1}$ mice develop severe myeloid bias and lymphopenia in the spleen and bone marrow.

To further confirm the presence of lymphopenia in these mice, we next analyzed the peripheral blood. Indeed, Casp $8^{\triangle E 385}$ ' We next analyzed the peripheral blood. Indeed, Casp 8
${ }_{\triangle E 385}$ Ripk $^{-/-}$and Casp $8^{\triangle E 385 / \triangle E 385} \mathrm{Mlkl}^{-/-}$mice showed a distinct decrease in white blood cell (WBC) and lymphocytes but normal numbers of monocytes and granulocytes in the blood (Fig. 5D). Interestingly, Casp $8^{\triangle E 385 / \triangle E 385}$ mice showed a minor increase in the WBC and lymphocyte counts (Fig. 5D). Furthermore, the total levels of $B$ cells $\left(C D 19^{+}\right)$, $T$ cells $\left(C D 3^{+}\right)$as well as mature $B$ cells $\left(\mathrm{B}_{220^{+}} \mathrm{IgM}^{+} / \mathrm{B} 2 \mathrm{O}^{+} \mathrm{CD} 19^{+}\right)$and $\mathrm{T}$ cells subsets $\left(\mathrm{CD} 3^{+} \mathrm{CD} 4^{+}\right.$ $\mathrm{CD}^{-} / \mathrm{CD}^{+} \mathrm{CD}^{+} \mathrm{CD}^{-}$) sharply decreased in the blood of Casp $8^{\triangle E 385 / \triangle E 385}$ Ripk3 $^{-/-}$and Casp $8^{\triangle E 385 / \triangle E 385} \mathrm{Mlkl}^{-1-}$ mice (Fig. 5E). Collectively, these results demonstrate that caspase- 8 cleavage associated with RIPK3 or MLKL plays a critical role in maintaining immune cell homeostasis.

In addition, $\mathrm{Ripk}^{-/-} \mathrm{Casp} 8^{-/-}$can rescue the postnatal lethality of Ripk $1^{-1-}$ mice by inhibiting both apoptosis and necroptosis $[67,68]$. Therefore, we examined whether CASP8( $\triangle E 385)$ combined with the ablation of Ripk3 contributed to the perinatal death of Ripk $1^{-/-}$mice. We generated Ripk $1^{-/}{ }^{-}$Ripk $3^{-/}{ }^{-}$Casp $8^{\Delta E 385 / \Delta E 385}$ mice by intercrossing Ripk $1^{+/}$Ripk3 ${ }^{-/-}$Casp $8^{\Delta E 385 / \Delta E 385}$ mice. Ripk $1^{-/-}$Ripk $^{-/-}$Casp $8^{\Delta E 385 / \triangle E 385}$ mice survived normally at birth; however, they were runted with apparent focal cutaneous lesions and scaling on the skin, and eventually died around two weeks after birth (Fig. 5F and S5A). These data suggest that caspase-8 cleavage mediated apoptosis combined with RIPK3 dependent necroptosis was partially responsible for the perinatal lethality of RIPK1 deficiency mice. This observation further confirmed that Caspase-8 cleavage is essential for apoptosis during development.

\section{Halve the expression of RIPK1 rescues transplantable lymphopenia in Casp8 ${ }^{\Delta E 385 / \Delta E 385}$ Ripk3 $^{-/-}$mice} Although Ripk $1^{-/-}$Ripk $^{-1-}$ Casp $8^{\triangle E 385 / \triangle E 385}$ mice did not survive to adulthood, we found that Ripk $1^{+/-}$Ripk $3^{-/-}$Casp $8^{\Delta E 385 / \triangle E 385}$ mice were viable beyond weaned and fertile. Furthermore, splenomegaly in Ripk $3^{-1}$ Casp $8^{\triangle E 385 / \triangle E 385}$ mice was largely suppressed in Ripk $1^{+/-}$Ripk3 ${ }^{-/-}$Casp $8^{\triangle E 385 / \Delta E 385}$ mice (Fig. 6A). Consistently, myeloid bias and lymphopenia in the spleen and lymphopenia in the bone marrow were also significantly relieved in Ripk $1^{+/}$Ripk3 $^{-/-} \operatorname{Casp}^{\Delta E 385 / \Delta E 385}$ mice compared to those in Ripk3 $^{-/-}$Casp $8^{\Delta E 385 / \triangle E 385}$ mice (Fig. 6B). In addition, Ripk ${ }^{+/-}$Ripk3 $^{-/-}$ Casp $8^{\triangle E 385 / \triangle E 385}$ mice exhibited normal immature and mature $B$ cells $\left(B 220^{+} \operatorname{lgM}^{+} / B_{22} 0^{\text {hi }} \mathrm{CD} 19^{\text {hi }}\right)$ in the bone marrow (Fig. S5B, D). Importantly, the complete blood count results showed increased WBC and lymphocyte in the peripheral blood of $\mathrm{Ripk}^{+/-}$ Ripk3 $^{-1-}$ Casp $^{\triangle E 385 / \triangle E 385}$ mice compared to WT mice (Fig. 6C), suggesting that lymphopenia and myeloid bias in Ripk3 ${ }^{-1-}$ Casp $8^{\triangle E 385 / \triangle E 385}$ mice were largely alleviated by halving RIPK1 dosage.

To further test whether RIPK1 kinase activity contributed to lymphopenia in Ripk $^{-/-}$Casp $8^{\triangle E 385 / \triangle E 385}$ mice, we generated Ripk1 ${ }^{K 45 A / K 45 A}$ Ripk $^{-/ 1}$ Casp $8^{\triangle E 385 / \triangle E 385}$ mice and observed that Ripk ${ }^{\text {K45A/K45A }}$ Ripk3 $^{-/-}$Casp $8^{\triangle E 385 / \triangle E 385}$ mice showed lymphopenia and myeloid bias similar to Ripk ${ }^{-/}$Casp $8^{\Delta E 385 / \Delta E 385}$ mice (Figs. 6A-C and S5B-D). Collectively, these results demonstrate that RIPK1 dosage-dependent and RIPK1 kinase-independent scaffold function contributes to lymphopenia and myeloid bias in Ripk3 $3^{-/-}$Casp $8^{\Delta E 385 / \triangle E 385}$ mice.

Next, we asked whether lymphopenia was intrinsic to Ripk3 ${ }^{-1-}$ Casp $8^{\Delta E 385 / \triangle E 385}$ and $\mathrm{Mlkl}^{-/-}$Casp $8^{\triangle E 385 / \triangle E 385}$ hematopoietic stem cells (HSCs). The complete bone marrow of Ripk3 ${ }^{-/-}$Casp $8^{\Delta E 385 /}$ $\triangle E 385$ and $\mathrm{Mlkl}^{-1}{ }^{-} \mathrm{Casp}^{\triangle E 385 / \triangle E 385}$ mice was transplanted into lethally irradiated syngeneic WT recipients (Fig. S6A). After hematopoiesis was reestablished, we observed that the mice receiving $\mathrm{Mlkl}^{-1-}$ Casp $8^{\triangle E 385 / \triangle E 385}$ bone marrow developed splenomegaly, whereas the spleen of Ripk ${ }^{-/-}$Casp $8^{\triangle E 385 / \Delta E 385}$ recipients showed no difference (Fig. S6B). In the peripheral blood, the

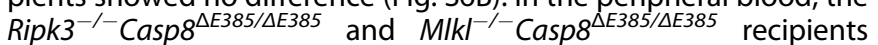
showed leucopenia and deficiency in every WBC subset (Fig. 6D), while the red blood cells, platelets, and hemoglobin levels showed a minor decrease (Fig. S6C). Consistently, lymphopenia was recapitulated in the Ripk $3^{-/-}$Casp $8^{\Delta E 385 / \Delta E 385}$ and $M / k^{-1-}$ Casp $8^{\triangle E 385 / \triangle E 385}$ recipients characterized by $\mathrm{CD}^{+} \mathrm{T}$ cell deficiency in blood and decreased B cells, T cells, and their subsets in the spleen, bone marrow, and blood (Figs. 6E, F and S6D). Collectively, caspase-8 cleavage together with RIPK3 or MLKL suppresses the intrinsic lymphopenia of hematopoietic stem cells.

\section{DISCUSSION}

Caspase- 8 is a key regulator of apoptosis and necroptosis, as well as the inflammatory response through its dimerization and enzymatic activity $[1,5,16]$. The auto-cleavage activity of Caspase- 8 has also been shown to be involved in mediating apoptosis and regulating inflammation [13].

In this study, we demonstrated that $\operatorname{CASP} 8(\triangle \mathrm{E} 385)$ not only compromised Fas-induced apoptosis and switched TNF-a induced apoptosis to necroptosis but also promoted necroptosis both in vitro and in vivo. However, in contrast to the embryonic lethality observed in caspase-8 deficient [49] or with catalytically inactive caspase-8 mice $[6,8]$, Casp $8^{\triangle E 385 / \Delta E 385}$ mice survived normally, suggesting that primarily caspase- 8 catalytic activity rather than caspase-8 cleavage contributes to the suppression of RIPK3-MLKL mediating necroptosis during embryo development.

In the current study, we observed that caspase-8 cleavage between the large and small subunits was increased under TNF-a/ Smac/zVAD (Fig. 1B), which is consistent with results from TNF-a plus ZVAD stimulation in previous studies $[69,70]$. It has also been suggested that pro-caspase- 8 and activated caspase- 8 have 
A

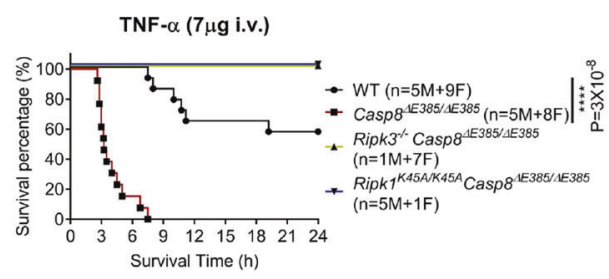

C

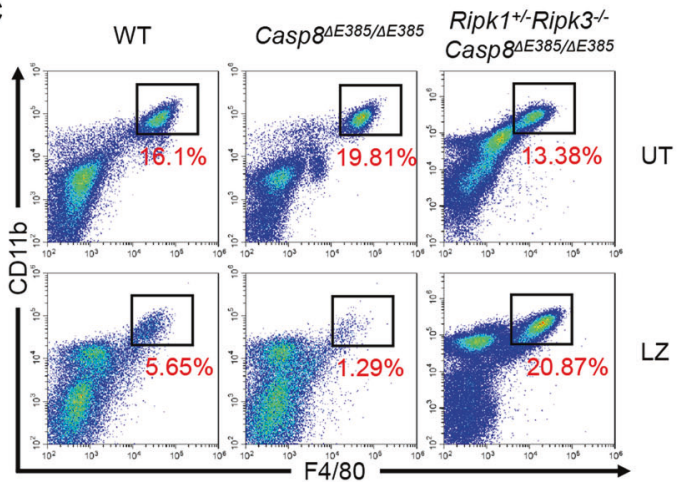

B

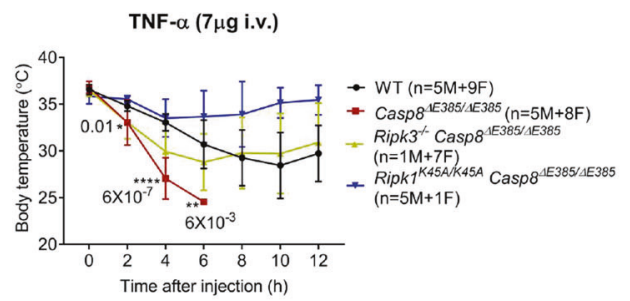

D

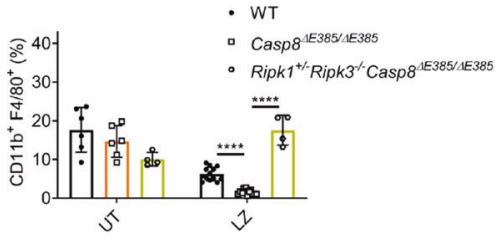

Fig. 4 The CASP8( $\Delta$ E385) promotes necroptosis in vivo. A Mouse survival curve of 8- to 16 -week old mice after injection by TNF- $\alpha$ ( $7 \mu$ g each mouse, i.v.). M, male, F, female. $P$ values alongside the asterisk, by two-sided Log-rank (Mantel-Cox) test. ${ }^{* * * *} p<0.0001$. B Body temperature of 8- to 16-week old mice after injection by TNF- $\alpha(7 \mu \mathrm{g}$ each mouse, i.v.). $M$, male, $F$, female. Bars, mean \pm SD. The significance of body temperature between WT and Casp $8^{\Delta E 385 / \Delta E 385}$ mice in the indicated time was described by $P$ values below the asterisk (unpaired, two-tailed $t$ test) ${ }^{*} p<0.05,{ }^{* *} p<0.01,{ }^{* * * *} p<0.0001$. C Representative peritoneal macrophages flow cytometric dot plots along CD11b versus F4/80 parameters. Untreated (UT), LPS + ZVAD (LZ). D Dot plots of CD $11 \mathrm{~b}^{+} \mathrm{F} 4 / 80^{+}$peritoneal macrophages of 8- to 12 -week old WT, Casp8 $8^{\triangle E 385 / \Delta E 385}$ and Ripk ${ }^{+/-}$Ripk3 $^{-/-}$Casp $8^{\triangle E 385 / \triangle E 385}$ mice. Bars, mean + SD. $P$ values (unpaired, two-tailed $t$ test) ${ }^{* * * *} p<0.0001$.

divergent substrate specificities [71, 72], and the substrate specificities of procaspase-8 change when it heterodimerizes with CFLIP $\mathrm{L}_{\mathrm{L}}$ in complex II [42]. It has also been shown that Z-VAD-FMK is less efficacious at inhibiting the caspase- 8 homodimer than the caspase-8/cFLIP $P_{L}$ heterodimer [73]. Thus, one possible explanation is that ZVAD promotes complex II formation, but its ability to inhibit the catalytic activity of pro-caspase- 8 is not as efficacious as to inhibit the activated caspase-8, which contributes to more caspase-8 auto-processing.

Earlier studies have demonstrated that perinatal death in Ripk $1^{-1-}$ mice is prevented by co-ablation of FADD/caspase- 8 dependent apoptosis and RIPK3/MLKL dependent necroptosis $[67,68]$. Here, we generated Ripk $1^{-1-} \operatorname{Ripk}^{-/-}$Casp $8^{\Delta E 385 / \Delta E 385}$ mice that died around two weeks to strongly prolong the survival of Ripk $1^{-1-}$ Ripk $^{-1-}$ mice. During the manuscript preparation, a recent paper reported that Fadd ${ }^{-/-} \mathrm{MlkI}^{-/}-\operatorname{Casp}^{\mathrm{DA} / D A}$ also died around two weeks after birth due to the exacerbation of inflammation [13], suggesting that caspase-8 exhibits a FADDindependent inflammatory function that is inhibited by caspase- 8 cleavage. Therefore, whether lethal inflammation in Ripk $1^{-1-}$ Ripk3 ${ }^{-1-}$ Casp $8^{\triangle E 385 / \triangle E 385}$ mice can be prevented by the additional ablation of caspase-1 as Fadd ${ }^{-1-} \mathrm{Mlkl}^{-1-} \mathrm{Casp}^{\mathrm{DA} / D A}$ mice remain to be determined.

The role of caspase- 8 , RIPK3, and MLKL in non-programmed cell death has been reported to regulate lymphadenopathy [11], lymphoproliferation [25] and immunodeficiency [26, 33]. We demonstrated an unexpected role of caspase- 8 auto-cleavage cooperating with RIPK3 or MLKL and RIPK1 in lymphopenia regulation. Unlike Casp $8^{-1-} \mathrm{Ripk}^{-1-}$ and $\mathrm{Casp} 8^{-1-} \mathrm{MlkI}^{-1-}$ mice, which resemble the human ALPS [11] and impair cytokine response [33], we found that Casp $8^{\Delta E 385 / \triangle E 385} \mathrm{Ripk}^{-/-}$and Casp $8^{\triangle E 385 / \triangle E 385} \mathrm{Mlkl}^{-1-}$ mice develop hematopoietic cell-intrinsic lymphopenia and myeloid bias (Figs. 5, 6). We observed that the circulating mature $\mathrm{B}$ cells $\left(\mathrm{B}_{2} 20^{+} \mathrm{IgM}^{+}\right)$and $\mathrm{T}$ cells in the peripheral blood and spleen of Casp $8^{\Delta E 385 / \Delta E 385}$ Ripk $^{-/-}$and Casp $8^{\triangle E 385 / \triangle E 385} \mathrm{Mlkl}^{-1-}$ mice were dramatically decreased. This can be explained by decreased immature and mature $B$ cells and $\mathrm{T}$ cells in the bone marrow (Fig. 5B-E). Moreover, Lymphopenia and myeloid bias in Ripk $3^{-/-}$Casp $8^{\triangle E 385 / \triangle E 385}$ mice were largely suppressed in Ripk $1^{+/-}$Ripk $^{-/-}$Casp $8^{\Delta E 385 / \Delta E 385}$ mice but not in Ripk $1^{K 45 A / K 45 A}$ Ripk3 $^{-/-}$Casp8 ${ }^{\triangle E 385 / \triangle E 385}$ mice, revealing a previously unknown role of the dosage of RIPK1 instead of RIPK1 kinase activity administered to the mice in maintaining immune cell homeostasis in Ripk ${ }^{-/-}$Casp $8^{\Delta E 385 / \triangle E 385}$ mice.

In this study, we identified the phenotypes of Casp $8^{\Delta E 385 / \Delta E 385}$ mice which resemble those of the Casp $8^{D A / D A}$ mice from a recent study [13]. Moreover, we also confirmed the enzymatic activity of CASP8( $\triangle \mathrm{E} 385)$ by examining caspase-3 cleavage in thymocytes with FasL treatment [46]. We found that Casp $8^{\triangle E 385 / \Delta E 385}$ thymocytes showed comparable level of caspase- 3 cleavage and cell death to that in Casp8 $8^{\text {D387A/D387A }}$ thymocytes after FasL treatment (Figs. $2 A$ and $S 2 A)$, which indicated CASP8( $\triangle E 385)$ has comparable enzymatic activity as caspase-8(D387A) [46]. However, we still cannot exclude the possibility that deletion of one amino acid in caspase-8 alters other caspase-8-mediated cellular signaling, therefore, whether E385 deletion influences other functions of caspase-8, in addition to its auto-cleavage, needs to be investigated further.

In summary, caspase- 8 auto-cleavage plays an important role in regulating cell death and immune cell homeostasis, that is, mediating apoptosis, suppressing necroptosis, and protecting from lymphopenia (Fig. S7). Although CASP8( $\triangle \mathrm{E} 385$ ) is sufficient to suppress necroptosis during embryonic development, CASP8 $(\Delta \mathrm{E} 385)$ can induce excessive necroptosis by switching apoptosis to necroptosis and promoting complex II assembly and stabilization. Accordingly, Casp $8^{\triangle E 385 / \triangle E 385}$ mice are strongly sensitized to 


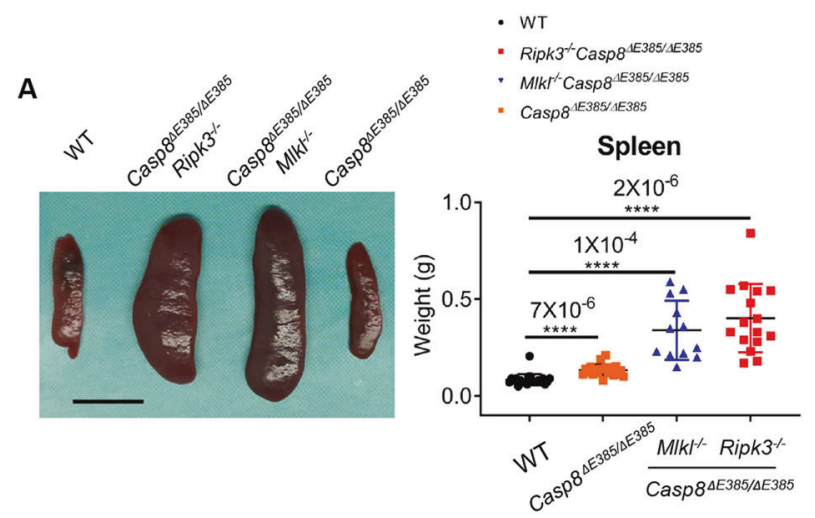

B

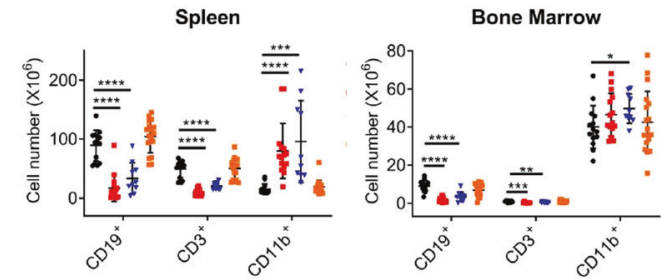

C

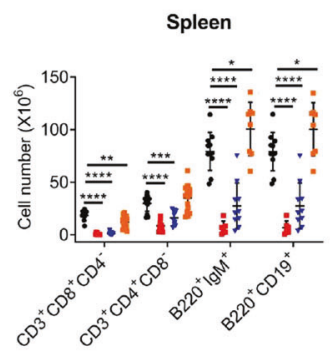

D

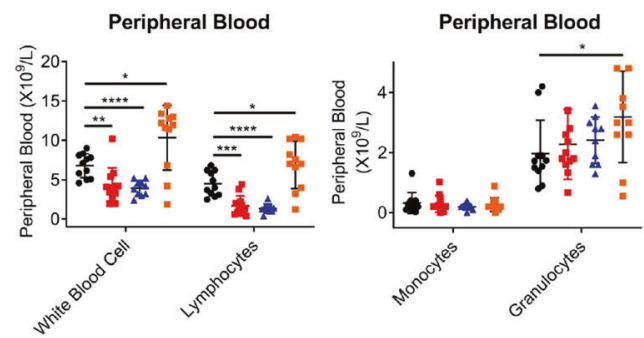

E

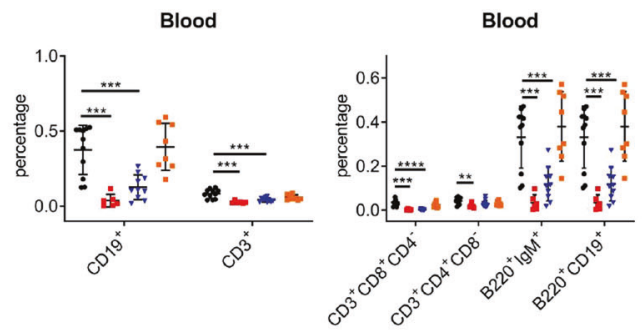

F

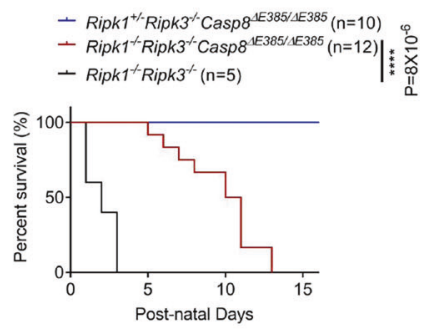

Fig. 5 Casp $8^{\Delta E 385 / \triangle E 385}$ Ripk3 $^{-/-}$mice develop serious lymphopenia and myeloid bias but prevent the postnatal lethality of Ripk ${ }^{-/-}$mice. A Spleens images (15 week) (left) and total spleen weight (14- to 17-week old) (right) of the indicated genotype mice. Scale bar, $1 \mathrm{~cm}$. Bars, mean \pm SD. $P$ values above the asterisk (unpaired, two-tailed $t$ test) ${ }^{* * *} p<0.0001$. B The immunocytes cell number in spleen and bone marrow (per tibia and femur) of 14- to 17-week old mice. Bars, mean \pm SD. $P$ values (unpaired, two-tailed $t$ test) ${ }^{*} p<0.05$, ${ }^{* *} p<0.01$, ${ }^{* * *} p<$ $0.001,{ }^{* * * *} p<0.0001$. C The B cell and T cell subsets cellularity in spleen and bone marrow (per tibia and femur) of 14- to 17-week old mice. Bars, mean \pm SD. $P$ values (unpaired, two-tailed $t$ test) ${ }^{*} p<0.05,{ }^{* *} p<0.01,{ }^{* * *} p<0.001,{ }^{* * * *} p<0.0001$. D The absolute cell number of the white blood cells and their subsets in the peripheral blood of 14 - to 17-week old mice. Bars, mean \pm SD. $P$ values (unpaired, two-tailed $t$ test) ${ }^{*} p<$ $0.05,{ }^{* *} p<0.01,{ }^{* * *} p<0.001,{ }^{* * * *} p<0.0001$. E The B cell and T cell subsets cellularity in the peripheral blood of 14- to 17-week old mice. Bars, mean \pm SD. $P$ values (unpaired, two-tailed $t$ test) ${ }^{* *} p<0.01,{ }^{* * *} p<0.001,{ }^{* * * *} p<0.0001$. F Mouse survival curve of the given genotypes after birth. $P$ values alongside the asterisk, two-sided Log-rank (Mantel-Cox) test, ${ }^{* * *} p<0.0001$.

TNF-a induced necroptosis in vivo. In addition, Casp $8^{\triangle E 385 /}$ ${ }_{\triangle E 385} \mathrm{Ripk}^{-1-}$ and Casp $8^{\Delta E 385 / \triangle E 385} \mathrm{Mlkl}^{-1-}$ mice develop severe lymphopenia that can be prevented by reducing the RIPK1 dosage by half, not by RIPK1 kinase inactive mutant. This indicates that caspase-8 cleavage cooperating RIPK3/MLKL to regulate RIPK1 scaffold-dependent but RIPK1 kinase-independent function contributes to the maintenance of immune cell homeostasis. The exact signaling pathway and mechanism require further investigation.

\section{MATERIALS AND METHODS}

\section{Mice}

All mice utilized in this study were C57BL/6 background and housed in a specific pathogen-free (SPF) facility. Both male and female mice were used in this study. For all studies mice were age- and sex-matched. Ripk $1^{+/-}$,

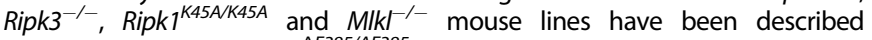
previously $[74,75]$. Casp $8^{\triangle E 385 / \triangle E 385}$ mice were generated by CRISPR-Cas 9 mutation system (Bioray Laboratories Inc., Shanghai, China). Three adjacent nucleotides AAG was removed in the exon 8 of the Casp 8 gene locus resulted in the deletion of Glutamic acid (Glu, E) in 385 position of caspase-8 protein sequence. The Casp8 (ID: 12370) gene region corresponds to genomic position chr1: 58844689-58844691. Casp $8^{\triangle E 385 / \triangle E 385}$ mice genotyping primers: $5^{\prime}$-CAGAGGCTCTGAGTAAGACC-3' and 5'-CTGAGGACATCTITCCCTCAG-3' amplified 506 bp DNA fragments for sequencing. Additional information is provided upon request. Animal experiments were conducted in accordance with the guidelines of the Institutional Animal Care and Use Committee of the Institute of Nutrition and Health, Shanghai Institutes for Biological Sciences, University of Chinese Academy of Sciences.

Isolation and culture of thymocytes, mouse dermal fibroblasts (MDFs) and bone marrow derived macrophages (BMDMs)

Both male and female mice were used to generate MDFs and BMDMs. MDFs were separated from the skin of newborn mice (P0-P1), and cultured in DMEM medium (SH30243.01B, HyClone) supplemented with $10 \%$ of Fetal Bovine Serum (04-001-1 A, Bioind) and 1\% of penicillin/streptomycin (15140122, Gibco). BMDMs were isolated from the bone marrow of mouse femurs and tibias followed by inducing to differentiate in vitro. Bone marrow cells were cultured for 7 days in RPMI-1640 medium (SH30809.01B, HyClone) containing $10 \%$ of Fetal Bovine Serum (04-001-1 A, Bioind) and $1 \%$ of penicillin/streptomycin (15140122, Gibco) and $50 \mathrm{ng} / \mathrm{ml} \mathrm{M-CSF}$ 
A
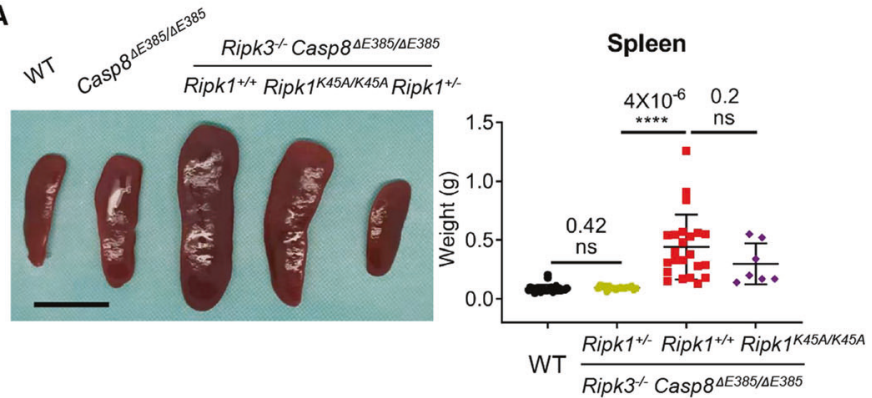

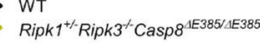

B

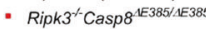

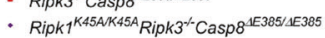

Spleen

$$
\text { IE385 }
$$

Bone Marrow

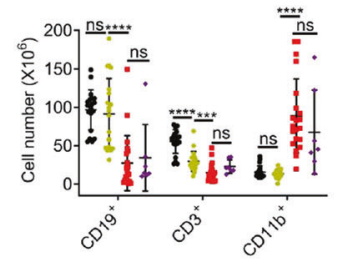

C

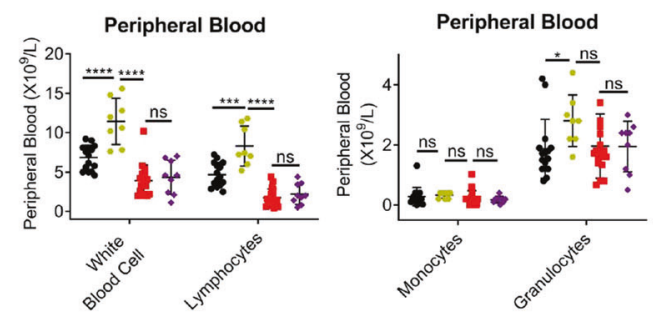

D

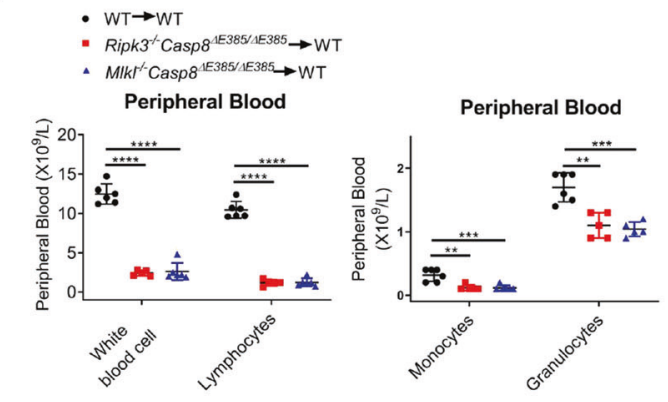

E
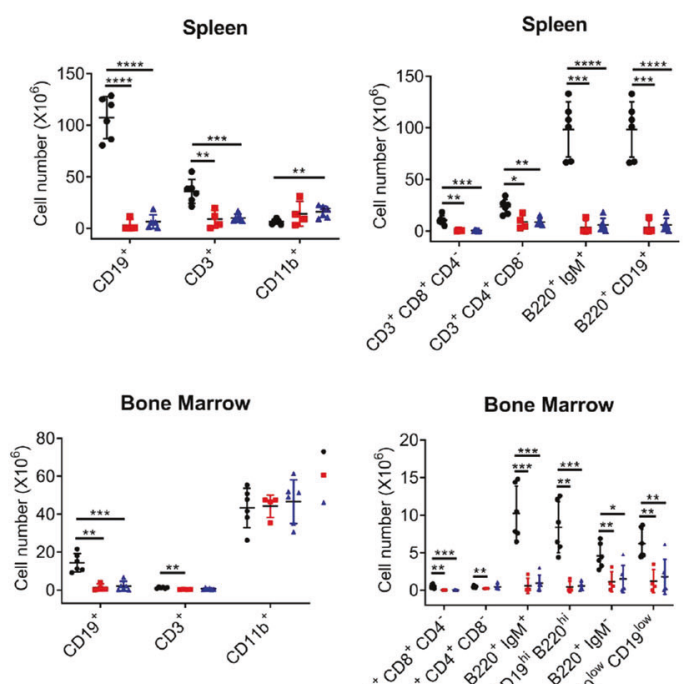

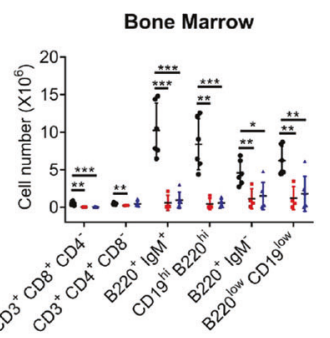

Fig. 6 Halving the RIPK1 dosage rescues transplantable lymphopenia and myeloid bias in Ripk3 ${ }^{-1-}$ Casp8 ${ }^{\triangle E 385 / \triangle E 385}$ mice. A Spleen images (12 week) (left) and total spleen weight (14-17 week) (right) showed normal sized spleen in the Ripk $1^{+/-}$Ripk $3^{-/-}$Casp $8^{\triangle E 385 / \triangle E 385}$ mice. Scale bar, $1 \mathrm{~cm}$. Bars, mean \pm SD. $P$ values above the asterisk (unpaired, two-tailed $t$ test) ${ }^{* * * *} p<0.0001 ;$ ns, no significance. B The absolute cell number of indicated immunocytes in spleen and bone marrow (per tibia and femur) of 14- to 17-week old age matched mice. Bars, mean \pm SD. $P$ values (unpaired, two-tailed $t$ test) ${ }^{* *} p<0.01,{ }^{* * *} p<0.001,{ }^{* * *} p<0.0001$; ns, no significance. C The cell number of white blood cells and their subsets in the peripheral blood of 14 - to 17 -week old mice. Bars, mean \pm SD. $P$ values (unpaired, two-tailed $t$ test) ${ }^{*} p<0.05$, ${ }^{* * * *} p<0.001,{ }^{* * * *} p<$ 0.0001 ; ns, no significance. D The absolute cell number and percentage of white blood cells and their subsets in the peripheral blood of 6 -month old recipients. Bars, mean \pm SD. $P$ values (unpaired, two-tailed $t$ test) ${ }^{*} p<0.05,{ }^{* *} p<0.01,{ }^{* * *} p<0.001,{ }^{* * * *} p<0.0001$. E The absolute cell number of the immunocytes and their subsets in the spleen of 6 -month old recipients. Bars, mean \pm SD. $P$ values (unpaired, two-tailed $t$ test) ${ }^{*} p<0.05,{ }^{* *} p<0.01,{ }^{* * *} p<0.001,{ }^{* * *} p<0.0001$. $\mathbf{F}$ The absolute cellularity of the immunocytes and their subsets in the bone marrow per tibia and femur of 6-month old recipients. Bars, mean \pm SD. $P$ values (unpaired, two-tailed $t$ test) ${ }^{*} p<0.05,{ }^{* *} p<0.01,{ }^{* * *} p<0.001$.

(AF-315-02, PeproTech), and medium was refreshed each 3 days. Cells were cultivated at $37^{\circ} \mathrm{C}$ with $5 \% \mathrm{CO}_{2}$.

\section{Cell death stimulation and cell survival assay}

MDFs were plated in 96-well plates $12 \mathrm{~h}$ before stimulation at a concentration of $1 \times 10^{4}$ cells per well. For TNF-a induced apoptosis and necroptosis stimulation, MDFs were treated with TNF-a $(20 \mathrm{ng} / \mathrm{ml})(\mathrm{T})$ for $10 \mathrm{~h}$, TNF-a $(20 \mathrm{ng} / \mathrm{ml})+$ Smac $(1 \mu \mathrm{M})(\mathrm{TS})$, TNF-a + Smac +Necrostatin-1 $(30 \mu \mathrm{M})($ TSN), TNF-a + Smac +zVAD $(20 \mu \mathrm{M})($ TSZ), TNF-a + Smac +zVAD+ Nec-1 (TSZN) for $6.45 \mathrm{~h}$, TNF-a $(20 \mathrm{ng} / \mathrm{ml})+\mathrm{CHX}(20 \mu \mathrm{g} / \mathrm{ml})(\mathrm{TC})$, TNF-a + $\mathrm{CHX}+$ Necrostatin-1 $(30 \mu \mathrm{M})(\mathrm{TCN})$, TNF- $\mathrm{a}+\mathrm{CHX}+\mathrm{zVAD}(20 \mu \mathrm{M})$ (TCZ), and TNF-a + CHX + zVAD+Nec-1 (TCZN) for $4.45 \mathrm{~h}$. For GSK' 872 induced apoptosis, MDFs were treated with GSK' 872 in concentration of $3 \mu \mathrm{M}, 6 \mu \mathrm{M}$ and $10 \mu \mathrm{M}$ for $10 \mathrm{~h}$, respectively.

BMDMs were plated in 96-well plates $12 \mathrm{~h}$ before stimulation at a concentration of $2 \times 10^{4}$ cells per well. For TNF-a, LPS and poly(l:C) induced apoptosis and necroptosis stimulation, BMDMs were treated with TNF-a (20 $\mathrm{ng} / \mathrm{ml})+$ Smac $(1 \mu \mathrm{M})+\mathrm{zVAD}(20 \mu \mathrm{M})(\mathrm{TSZ}), \mathrm{TNF}-\mathrm{a}+\mathrm{Smac}+\mathrm{zVAD}+\mathrm{Nec}-1$ $(30 \mu \mathrm{M})(\mathrm{TSZN})$, LPS $(100 \mathrm{ng} / \mathrm{ml})(\mathrm{L})$, LPS $(100 \mathrm{ng} / \mathrm{ml})+\mathrm{zVAD}(20 \mu \mathrm{M})(\mathrm{LZ}), \mathrm{LPS}+$ zVAD + Nec-1 $(30 \mu \mathrm{M})(\mathrm{LZN})$, poly(l:C) $(100 \mu \mathrm{g} / \mathrm{ml})(P)$, poly(l:C) $(100 \mu \mathrm{g} / \mathrm{ml})+$ zVAD $(20 \mu \mathrm{M})(\mathrm{PZ})$, poly(l:C) + zVAD + Nec-1 $(30 \mu \mathrm{M})(\mathrm{PZN})$ for $3 \mathrm{~h}$.
Thymocytes were plated in 96-well plates $12 \mathrm{~h}$ before stimulation at a concentration of $4 \times 10^{4}$ cells per well. For Fas-induced apoptosis, thymocytes were treated with anti-Fas antibody $(J o-2,100 \mathrm{ng} / \mathrm{ml})+\mathrm{CHX}$ $(30 \mu \mathrm{g} / \mathrm{ml})(\mathrm{FC})$ for $12 \mathrm{~h}, 15 \mathrm{~h}, 18 \mathrm{~h}$ and $21 \mathrm{~h}$, respectively.

Cell survival was determined using the CellTiter-Glo Luminescent Cell Viability Assay kit (G7572, Promega) and the luminescence was recorded with a microplate luminometer (5300170, Thermo Scientific).

\section{Cell death analysis by western blot (WB) and complex II immunoprecipitation}

MDFs were plated in $6-\mathrm{cm}$ dishes $12 \mathrm{~h}$ before stimulation at a concentration of $2 \times 10^{6}$ cells per dish. For TNF-a induced apoptosis and necroptosis stimulation, MDFs were treated with TNF-a $(40 \mathrm{ng} / \mathrm{ml})+\mathrm{Smac}$ $(2 \mu \mathrm{M})(\mathrm{TS})$, TNF-a $(20 \mathrm{ng} / \mathrm{ml})+$ Smac $(1 \mu \mathrm{M})+\mathrm{zVAD}(20 \mu \mathrm{M})(\mathrm{TSZ})$, TNF-a $(40 \mathrm{ng} / \mathrm{ml})+\mathrm{CHX}(40 \mu \mathrm{g} / \mathrm{ml})(\mathrm{TC}), \mathrm{TNF}-\mathrm{a}(40 \mathrm{ng} / \mathrm{ml})+\mathrm{CHX}(40 \mu \mathrm{g} / \mathrm{ml})+$ zVAD $(20 \mu \mathrm{M})(\mathrm{TCZ})$ for the indicated time. For GSK'872 induced apoptosis, MDFs were treated with GSK' $872(20 \mu \mathrm{M})$ for the indicated time.

BMDMs were plated in $6-\mathrm{cm}$ dishes $12 \mathrm{~h}$ before stimulation at a concentration of $2 \times 10^{6}$ cells per dish. For LPS induced necroptosis stimulation, BMDMs were treated with LPS $(200 \mathrm{ng} / \mathrm{ml})(\mathrm{L}), \mathrm{LPS}+\mathrm{zVAD}$ $(40 \mu \mathrm{M})(\mathrm{LZ})$ for $6 \mathrm{~h}$. 
Cells were harvested after stimulation, washed with PBS and lysates with RIPA lysis buffer (50 mM Tris- $\mathrm{HCl}$ (pH7.4), $150 \mathrm{mM} \mathrm{NaCl}, 2$ mM EDTA, $1 \%$ NP-40, 0.1\% SDS, Protease inhibitor Cocktail (4693132001, Roche), Phosphatase inhibitor Cocktail 3 (P0044-1ML, Sigma)) for 30-45 min on ice. The lysates were centrifuged for $20 \mathrm{~min}$ at $13,200 \mathrm{~g}, 4^{\circ} \mathrm{C}$, quantified by BCA kit (P0010S, Beyotime) and then mixed with SDS sample buffer (250 mM Tris-Cl (PH 6.8), 10\% SDS, 30\% Glycerol, 5\% $\beta$-mercapitalethanol, $0.02 \%$ Bromophenol blue) followed by boiling at $100{ }^{\circ} \mathrm{C}$ for $10 \mathrm{~min}$. The proteins were separated by SDS-PAGE, and then transferred to PVDF membrane (IPVH00010, Millipore) at $110 \mathrm{v}$ for $3 \mathrm{~h}$. Membranes were blocked with $5 \%$ skimmed milk in PBST $0.1 \%$ for $1 \mathrm{~h}$. Membranes were washed three times with PBST $0.1 \%$ for $7 \mathrm{~min}$. Membranes were incubated in PBST $0.1 \%$ containing primary antibodies at $4{ }^{\circ} \mathrm{C}$ overnight. The proteins were detected by chemiluminescent substrate (34080, Thermo Scientific) using Tanon 5200 Multi Luminescent Imaging Workstation (Tanon). For mouse tissue protein extraction, the indicated tissues were ground into powder by pestle and mortar with liquid nitrogen, and the protein was extracted with RIPA lysis buffer followed by centrifugation, quantification, SDS-PAGE and transmembrane as above. For GSK'872 induced apoptosis detection in Fig. 2B, the MDFs were harvested by RIPA lysis buffer with $6 \mathrm{M}$ Urea.

For complex II immunoprecipitation (IP), cells were lysed with lysis buffer (20 mM Tris- $\mathrm{HCl}$ (pH 7.5), 1\% Triton X-100, 0.2\% NP-40, $120 \mathrm{mM} \mathrm{NaCl}, 0.27 \mathrm{M}$ sucrose, $1 \mathrm{mM}$ EDTA, $1 \mathrm{mM}$ EGTA, $50 \mathrm{mM} \mathrm{NaF}, 10 \mathrm{mM} \beta$-glycerophosphate, $5 \mathrm{mM}$ sodium pyrophosphate, $2 \mathrm{mM}$ PMSF, Protease inhibitor Cocktail (4693132001, Roche), Phosphatase inhibitor Cocktail 3 (P0044-1ML, Sigma)). Cell lysates were overnight incubated with $1 \mu \mathrm{g}$ of anti-RIPK1 $(610459$, BD Biosciences) at $4{ }^{\circ} \mathrm{C}$ followed by $4 \mathrm{~h}$ incubation with $50 \mu \mathrm{l}$ of Protein A agarose (16-125, Millipore). Beads were washed and proteins were eluted with 2 X SDS sample buffer followed by boiling at $100^{\circ} \mathrm{C}$ for $10 \mathrm{~min}$.

The primary antibodies used for western blot: anti-RIPK1 (610459, BD Biosciences), anti-phosphorylated RIPK1 (31122 S, Cell Signaling Technology), anti-RIPK3 (2283, Prosci), anti-phosphorylated RIPK3 (ab195117, Abcam), anti-caspase-8 (ALX-804-447-C100, Enzo Life Science), anticleaved caspase-8 (9429S, Cell Signaling Technology), anti-caspase-8 (4927 S, Cell Signaling Technology), anti-MLKL (AP14272b, Abgent), antiphosphorylated MLKL (ab196436, Abcam), anti-FADD (ab124812, Abcam), anti-PARP (9542 S, Cell Signaling Technology), anti-caspase-3 (9662 S, Cell Signaling Technology), anti-cleaved caspase-3 (9661 S, Cell Signaling Technology), anti- $\beta$-actin (3779, Prosci), anti-GAPDH (G9545, Sigma).

\section{Anti-Fas induced thymocytes apoptosis analyzed by flow cytometry and western blot}

Both male and female mice were used to harvest thymocytes. Thymocytes were harvested from wild-type and Casp $8^{\triangle E 385 / \triangle E 385}$ mice of 1-month old, and cultured in DMEM medium (SH30243.01B, HyClone) supplemented with $10 \%$ of heat-inactivated Fetal Bovine Serum (04-001-1 A, Bioind), $1 \%$ of penicillin/streptomycin (15140122, Gibco), $200 \mathrm{mM}$ L-glutamine (25030081, Gibco), 1X MEM non-essential amino acids (NEAA) (11140-050, Gibco) and $55 \mathrm{mM}$ 2-Mercaptoethanol (M6250, Sigma). Cells were cultivated at $37^{\circ} \mathrm{C}$ with $5 \% \mathrm{CO}_{2}$.

For flowcytometry analysis, thymocytes were plated in 6-well plates followed by stimulation at a concentration of $1 \times 10^{6}$ cells per well, and thymocytes were treated with $2 \mu \mathrm{g} / \mathrm{ml}$ anti-Fas antibody (Jo-2, 554255, BD) for $24 \mathrm{~h}$ followed by staining with FITC-Annexin $\mathrm{V}$ and PI utilizing apoptosis detection kit (C1062L, Beyotime). After staining, cells were analyzed in cytoflex S flow cytometer (cytoflex S, Beckman Coulter). All analyses were performed using CytExpert software (CytExpert, Beckman Coulter, Inc.).

For western blot analysis, thymocytes were plated in $10-\mathrm{cm}$ dish followed by stimulation at a concentration of $2 \times 10^{7}$ cells per well, and thymocytes were treated with $1 \mu \mathrm{g} / \mathrm{ml}$ anti-Fas antibody (Jo-2, 554255, BD) for the indicated time followed by washing with 1XPBS and lysates with RIPA lysis buffer (50 mM Tris-HCl (pH7.4), $150 \mathrm{mM} \mathrm{NaCl}, 2 \mathrm{mM}$ EDTA, $1 \%$ NP-40, $0.1 \%$ SDS, Protease inhibitor Cocktail (4693132001, Roche), Phosphatase inhibitor Cocktail 3 (P0044-1ML, Sigma)).

\section{MLKL oligomerization detection}

MDFs were cultured in $6-\mathrm{cm}$ dishes at a concentration of $2 \times 10^{6}$ cells per dish and challenged by TNF-a $(20 \mathrm{ng} / \mathrm{ml})+$ Smac $(1 \mu \mathrm{M})+\mathrm{zVAD}(20 \mu \mathrm{M})$ for the indicated time. MDFs were harvested at different time points and lysed with non-reducing sample buffer (125 mM Tris-Cl (PH 6.8), 20\% Glycerol, $0.02 \%$ Bromophenol blue) immediately. Total cell lysates were separated using SDS-PAGE, transferred to PVDF membrane (IPVH00010, Millipore), and detected with the indicated antibodies.
Anti-Fas induced hepatocellular apoptosis and analysis of the serum and liver damage

The wild-type and Casp8 ${ }^{\triangle E 385 / \triangle E 385}$ mice of 8- to 12-week old were injected intravenously with anti-Fas antibody (Jo-2, 554255, BD) in the dose of 0.5 $\mu \mathrm{g} / \mathrm{g}$ and their survival time was followed for $20 \mathrm{~h}$. At the indicated times, their livers and peripheral blood were harvested followed by processing for histological analysis, western blot and analyzing the alanine transaminase (ALT) and aspartate transaminase (AST) levels in serum. To analyze the ALT and AST levels in serum, the peripheral blood of the indicated mice were collected in anticoagulation tube followed by centrifugation at $7000 \mathrm{~g}, 4^{\circ} \mathrm{C}$ for $30 \mathrm{~min}$. The serum was collected to detect ALT (3040280, Shanghai Shensuo UNF Medical Diagnostic Articles Co.) and AST (3050280, Shanghai Shensuo UNF Medical Diagnostic Articles Co.) level utilizing the kit.

\section{TNF- $\alpha$ induced mice toxicity and analysis of the body} temperature

The WT, Casp $8^{\triangle E 385 / \triangle E 385}, \operatorname{Casp}^{\triangle E 385 / \triangle E 385} \mathrm{Ripk}^{-1-}$ and Casp $8^{\triangle E 385 /}$ ${ }_{\triangle E 385}$ Ripk $1^{\text {K45A/K45A }}$ mice of 8 - to 16 -week old were injected intravenously with TNF-a (CRT192C, Cell sciences and obtained from Dr. Yi Zhang at Shanghai Institute of Nutrition and Health, CAS) in the dose of $7 \mu \mathrm{g}$ each mouse and their body temperature was measured every $2 \mathrm{~h}$ until the twelfth hour after injection.

\section{Flow cytometry analyses}

Lymphocytes were isolated from the peripheral blood, spleen, bone marrow and lymph nodes of the indicated mice. Total cell numbers were counted using counting slides (SD-100, Nexcelom) in Cellometer Mini Automated Cell Counter (Nexcelom). Surface antigens were stained with indicated conjugated primary antibodies in the staining buffer $(1 \times \mathrm{PBS}, 3 \%$ BSA, $1 \mathrm{mM}$ EDTA, $0.1 \% \mathrm{NaN}_{3}$ ) at $4{ }^{\circ} \mathrm{C}$ for $30 \mathrm{~min}$. Antibodies used are asfollows: FITC anti-CD3 (11-0031-82, eBioscience), APC Cy7 anti-CD4 (552051, BD Biosciences), PerCp anti-CD8 (100732, Biolegend), PE anti-B220 (12-0452-83, eBioscience), APC anti-B220 (17-0452-83, eBioscience), APC anti-CD11b (17-0112-83, eBioscience), Brilliant Violet 421 anti-CD11b (562605, BD Biosciences), PE Cy7 anti-CD19 (25-0193-82, eBioscience), FITC anti-IgM (115-097-020, Jackson Laboratories), FITC anti-F4/80 (114801-85, eBioscience) were used for flow cytometry analysis in this study. After staining, cells were washed once with 1XPBS and immediately analyzed by in cytoflex S flow cytometer (cytoflex S, Beckman Coulter). All analyses were performed using CytExpert software (CytExpert, Beckman Coulter, Inc.).

\section{Analyses of $\mathrm{CD}^{11 \mathbf{b}^{+}} \mathrm{F4} / 80^{+}$peritoneal macrophages in vivo} Wild-type, Casp $8^{\triangle E 385 / \Delta E 385}$ and Ripk $1^{+/-}$Ripk3 ${ }^{-/-}$Casp $8^{\triangle E 385 / \Delta E 385}$ mice were injected intraperitoneally with vehicle or zVAD $(20 \mathrm{mg} / \mathrm{kg}) 1 \mathrm{~h}$ before intraperitoneal injection with PBS or LPS (10 mg/kg). Animals were killed at twenty fourth hour after the first injection, resident peritoneal cells were harvested by lavage of the peritoneal cavity with $8 \mathrm{ml} \mathrm{PBS}$. CD $11 \mathrm{~b}^{+} \mathrm{F} 4 / 80^{+}$ peritoneal macrophages were analyzed by flow cytometry.

\section{Bone marrow transplantation assay}

All of the recipient mice were wild type with C57BL/6 background, which received $11 \mathrm{~Gy}$ of total body irradiation in a split dose (550 rads) with 4-hour rest between doses using a Cesium-137 irradiator. Irradiated recipients were reconstituted by intravenous injection of $2.5 \times 10^{6}$ bone marrow cells from femurs and tibias of the 6-week old indicated genotype mice. Recipients were sacrificed at fourth months after reconstitution.

\section{Whole blood count analysis}

The whole peripheral blood of the indicated mice was collected in anticoagulation tube followed by diluting in EDTA buffer (0.5 M EDTA $\mathrm{pH} 8.0)$ at a ratio of 1:1, and then diluted peripheral blood was analyzed on an auto hematology analyzer (BC-2800Vet, Mindray).

\section{Quantification and statistical analysis}

Please refer to the figure legends for description of sample size $(n)$ and statistical significance. Data were analyzed with GraphPad Prism 8.0 software using the two-tailed unpaired Student $t$ test or two-sided Log-rank (Mantel-Cox) test. Bars, mean \pm standard deviation (mean $\pm S D$ ). Differences were considered statistically significant when the $P<0.05$, where $* * * * p<0.0001, * * * p<0.001, * * p<0.01, * p<0.05, \mathrm{~ns}$, not significant. 


\section{DATA AVAILABILITY}

The authors declare that all data supporting the findings of this study are present in the paper and/or the Supplementary Materials.

\section{REFERENCES}

1. Kesavardhana S, Malireddi RKS, Kanneganti TD. Caspases in cell death, inflammation, and pyroptosis. Annu Rev Immunol. 2020;38:567-95.

2. Lavrik IN, Golks A, Krammer PH. Caspases: pharmacological manipulation of cell death. J Clin Invest. 2005;115:2665-72.

3. Salvesen GS, Walsh CM. Functions of caspase 8: the identified and the mysterious. Semin Immunol. 2014;26:246-52.

4. Tummers B, Green DR. Caspase-8: regulating life and death. Immunol Rev 2017;277:76-89.

5. Van Opdenbosch N, Lamkanfi M. Caspases in cell death, inflammation, and disease. Immunity. 2019;50:1352-64.

6. Fritsch M, Gunther SD, Schwarzer R, Albert MC, Schorn F, Werthenbach JP, et al. Caspase-8 is the molecular switch for apoptosis, necroptosis and pyroptosis. Nature. 2019;575:683-7.

7. Newton K, Wickliffe KE, Dugger DL, Maltzman A, Roose-Girma M, Dohse M, et al. Cleavage of RIPK1 by caspase- 8 is crucial for limiting apoptosis and necroptosis. Nature. 2019;574:428-31.

8. Newton K, Wickliffe KE, Maltzman A, Dugger DL, Reja R, Zhang Y, et al. Activity of caspase-8 determines plasticity between cell death pathways. Nature. 2019;575:679-82

9. Kaiser WJ, Upton JW, Long AB, Livingston-Rosanoff D, Daley-Bauer LP, Hakem R, et al. RIP3 mediates the embryonic lethality of caspase-8-deficient mice. Nature. 2011;471:368-72.

10. Oberst A, Dillon CP, Weinlich R, McCormick LL, Fitzgerald P, Pop C, et al. Catalytic activity of the caspase-8-FLIP(L) complex inhibits RIPK3-dependent necrosis. Nature. 2011;471:363-7.

11. Alvarez-Diaz S, Dillon $C P$, Lalaoui N, Tanzer MC, Rodriguez DA, Lin A, et al. The Pseudokinase MLKL and the Kinase RIPK3 have distinct roles in autoimmune disease caused by loss of death-receptor-induced apoptosis. Immunity. 2016;45:513-26.

12. Kang S, Fernandes-Alnemri T, Rogers C, Mayes L, Wang Y, Dillon C, et al. Caspase8 scaffolding function and MLKL regulate NLRP3 inflammasome activation downstream of TLR3. Nat Commun. 2015;6:7515.

13. Tummers B, Mari L, Guy CS, Heckmann BL, Rodriguez DA, Ruhl S, et al. Caspase-8dependent inflammatory responses are controlled by its adaptor, FADD, and necroptosis. Immunity. 2020;52:994-1006.

14. Henry CM, Martin SJ. Caspase-8 acts in a non-enzymatic role as a scaffold for assembly of a pro-inflammatory "FADDosome" Complex upon TRAIL Stimulation. Mol Cell. 2017;65:715-29.

15. Kang TB, Yang SH, Toth B, Kovalenko A, Wallach D. Caspase-8 blocks kinase RIPK3 mediated activation of the NLRP3 inflammasome. Immunity. 2013:38:27-40.

16. Monie TP, Bryant CE. Caspase-8 functions as a key mediator of inflammation and pro-IL-1beta processing via both canonical and non-canonical pathways. Immunol Rev. 2015;265:181-93.

17. Gunther C, Buchen B, He GW, Hornef M, Torow N, Neumann H, et al. Caspase-8 controls the gut response to microbial challenges by Tnf-alpha-dependent and independent pathways. Gut. 2015;64:601-10.

18. Gunther C, Martini E, Wittkopf N, Amann K, Weigmann B, Neumann $\mathrm{H}$, et al Caspase-8 regulates TNF-alpha-induced epithelial necroptosis and terminal ileitis. Nature. 2011;477:335-9.

19. Weinlich $R$, Oberst A, Dillon $C P$, Janke $\amalg$, Milasta $S$, Lukens JR, et al. Protective roles for caspase-8 and cFLIP in adult homeostasis. Cell Rep. 2013;5:340-8.

20. Schwarzer $\mathrm{R}$, Jiao $\mathrm{H}$, Wachsmuth $\mathrm{L}$, Tresch A, Pasparakis M. FADD and Caspase- 8 regulate gut homeostasis and inflammation by controlling MLKL- and GSDMDmediated death of intestinal epithelial cells. Immunity. 2020;52:978-93.

21. Kovalenko A, Kim JC, Kang TB, Rajput A, Bogdanov K, Dittrich-Breiholz O, et al. Caspase-8 deficiency in epidermal keratinocytes triggers an inflammatory skin disease. J Exp Med. 2009;206:2161-77.

22. Newton K, Dugger DL, Wickliffe KE, Kapoor N, de Almagro MC, Vucic D, et al. Activity of protein kinase RIPK3 determines whether cells die by necroptosis or apoptosis. Science. 2014:343:1357-60.

23. Yang ZH, Wu XN, He P, Wang X, Wu J, Ai T, et al. A non-canonical PDK1-RSK signal diminishes pro-caspase-8-mediated necroptosis blockade. Mol Cell. 2020;80:296-310.

24. Mandal P, Feng Y, Lyons JD, Berger SB, Otani S, DeLaney A, et al. Caspase-8 collaborates with caspase- 11 to drive tissue damage and execution of endotoxic shock. Immunity. 2018;49:42-55.

25. Kanderova V, Grombirikova H, Zentsova I, Reblova K, Klocperk A, Fejtkova M, et al. Lymphoproliferation, immunodeficiency and early-onset inflammatory bowel disease associated with a novel mutation in Caspase 8. Haematologica. 2019;104:e32-4.
26. Chun HJ, Zheng L, Ahmad M, Wang J, Speirs CK, Siegel RM, et al. Pleiotropic defects in lymphocyte activation caused by caspase- 8 mutations lead to human immunodeficiency. Nature. 2002;419:395-9.

27. Niemela J, Kuehn HS, Kelly C, Zhang M, Davies J, Melendez J, et al. Caspase-8 deficiency presenting as late-onset multi-organ lymphocytic infiltration with granulomas in two adult siblings. J Clin Immunol. 2015;35:348-55.

28. La O, Tai L, Lee L, Kruse EA, Grabow S, Fairlie WD, et al. Membrane-bound Fas ligand only is essential for Fas-induced apoptosis. Nature. 2009;461:659-63.

29. Watanabe-Fukunaga R, Brannan Cl, Copeland NG, Jenkins NA, Nagata S. Lymphoproliferation disorder in mice explained by defects in Fas antigen that mediates apoptosis. Nature. 1992;356:314-7.

30. Watanabe-Fukunaga R, Brannan Cl, Copeland NG, Jenkins NA, Nagata S. Pillars article: lymphoproliferation disorder in mice explained by defects in Fas antigen that mediates apoptosis. 1992. J Immunol. 2012;189:5101-4.

31. Shah S, Wu E, Rao VK, Tarrant TK. Autoimmune lymphoproliferative syndrome: an update and review of the literature. Curr Allergy Asthma Rep. 2014;14:462.

32. Rieux-Laucat F, Le Deist F, Hivroz $C$, Roberts IA, Debatin KM, Fischer A, et al. Mutations in Fas associated with human lymphoproliferative syndrome and autoimmunity. Science. 1995;268:1347-9.

33. Gitlin AD, Heger K, Schubert AF, Reja R, Yan D, Pham VC, et al. Integration of innate immune signaling by caspase-8 cleavage of N4BP1. Nature. 2020;587:275-80.

34. Lehle AS, Farin HF, Marquardt $B$, Michels BE, Magg $T$, Li $Y$, et al. Intestinal inflammation and dysregulated immunity in patients with inherited caspase- 8 deficiency. Gastroenterology. 2019;156:275-8.

35. Boatright KM, Renatus M, Scott FL, Sperandio S, Shin H, Pedersen IM, et al. A unified model for apical caspase activation. Mol Cell. 2003;11:529-41.

36. Donepudi M, Mac Sweeney A, Briand C, Grutter MG. Insights into the regulatory mechanism for caspase-8 activation. Mol Cell. 2003;11:543-9.

37. Oberst A, Pop C, Tremblay AG, Blais V, Denault JB, Salvesen GS, et al. Inducible dimerization and inducible cleavage reveal a requirement for both processes in caspase-8 activation. J Biol Chem. 2010;285:16632-42.

38. Muzio M, Stockwell BR, Stennicke HR, Salvesen GS, Dixit VM. An induced proximity model for caspase-8 activation. J Biol Chem. 1998;273:2926-30.

39. Salvesen GS, Dixit VM. Caspase activation: the induced-proximity model. Proc Natl Acad Sci USA. 1999;96:10964-7.

40. Pop C, Fitzgerald P, Green DR, Salvesen GS. Role of proteolysis in caspase-8 activation and stabilization. Biochemistry. 2007;46:4398-407.

41. O'Donnell MA, Perez-Jimenez E, Oberst A, Ng A, Massoumi R, Xavier R, et al. Caspase 8 inhibits programmed necrosis by processing CYLD. Nat Cell Biol 2011;13:1437-42.

42. Pop C, Oberst A, Drag M, Van Raam BJ, Riedl SJ, Green DR, et al. FLIP(L) induces caspase 8 activity in the absence of interdomain caspase 8 cleavage and alters substrate specificity. Biochem J. 2011;433:447-57.

43. Lin Y, Devin A, Rodriguez Y, Liu ZG. Cleavage of the death domain kinase RIP by caspase-8 prompts TNF-induced apoptosis. Genes Dev. 1999;13:2514-26.

44. Feng $S$, Yang Y, Mei Y, Ma L, Zhu DE, Hoti N, et al. Cleavage of RIP3 inactivates its caspase-independent apoptosis pathway by removal of kinase domain. Cell Signal. 2007;19:2056-67.

45. Pop C, Timmer J, Sperandio S, Salvesen GS. The apoptosome activates caspase- 9 by dimerization. Mol Cell. 2006;22:269-75.

46. Kang TB, Oh GS, Scandella E, Bolinger B, Ludewig B, Kovalenko A, et al. Mutation of a self-processing site in caspase- 8 compromises its apoptotic but not its nonapoptotic functions in bacterial artificial chromosome-transgenic mice. J Immunol. 2008;181:2522-32.

47. Yao Z, Duan S, Hou D, Heese K, Wu M. Death effector domain DEDa, a self-cleaved product of caspase-8/Mch5, translocates to the nucleus by binding to ERK1/2 and upregulates procaspase- 8 expression via a p53-dependent mechanism. EMBO J. 2007;26:1068-80.

48. Thornberry NA, Rano TA, Peterson EP, Rasper DM, Timkey T, Garcia-Calvo M, et al. A combinatorial approach defines specificities of members of the caspase family and granzyme B. Functional relationships established for key mediators of apoptosis. J Biol Chem. 1997;272:17907-11.

49. Varfolomeev EE, Schuchmann M, Luria V, Chiannilkulchai N, Beckmann JS, Mett IL, et al. Targeted disruption of the mouse Caspase 8 gene ablates cell death induction by the TNF receptors, Fas/Apo1, and DR3 and is lethal prenatally. Immunity. 1998:9:267-76.

50. Mandal P, Berger SB, Pillay S, Moriwaki K, Huang C, Guo H, et al. RIP3 induces apoptosis independent of pronecrotic kinase activity. Mol Cell. 2014;56:481-95.

51. Orning $P$, Lien E. Multiple roles of caspase- 8 in cell death, inflammation, and innate immunity. J Leukoc Biol. 2021;109:121-41.

52. He S, Wang L, Miao L, Wang T, Du F, Zhao L. et al. Receptor interacting protein kinase-3 determines cellular necrotic response to TNF-alpha. Cell. 2009;137:1100-11. 
53. Cho YS, Challa S, Moquin D, Genga R, Ray TD, Guildford M, et al. Phosphorylationdriven assembly of the RIP1-RIP3 complex regulates programmed necrosis and virus-induced inflammation. Cell. 2009;137:1112-23.

54. Zhang DW, Shao J, Lin J, Zhang N, Lu BJ, Lin SC, et al. RIP3, an energy metabolism regulator that switches TNF-induced cell death from apoptosis to necrosis. Science. 2009:325:332-6.

55. Sun L, Wang H, Wang Z, He S, Chen S, Liao D, et al. Mixed lineage kinase domainlike protein mediates necrosis signaling downstream of RIP3 kinase. Cell. 2012;148:213-27.

56. Wang H, Sun L, Su L, Rizo J, Liu L, Wang LF, et al. Mixed lineage kinase domainlike protein MLKL causes necrotic membrane disruption upon phosphorylation by RIP3. Mol Cell. 2014;54:133-46.

57. He S, Wang X. RIP kinases as modulators of inflammation and immunity. Nat Immunol. 2018;19:912-22.

58. Wang L, Du F, Wang X. TNF-alpha induces two distinct caspase-8 activation pathways. Cell. 2008;133:693-703.

59. Micheau O, Tschopp J. Induction of TNF receptor I-mediated apoptosis via two sequential signaling complexes. Cell. 2003;114:181-90.

60. Wilson NS, Dixit V, Ashkenazi A. Death receptor signal transducers: nodes of coordination in immune signaling networks. Nat Immunol. 2009;10:348-55.

61. Zhao J, Jitkaew S, Cai Z, Choksi S, Li Q, Luo J, et al. Mixed lineage kinase domainlike is a key receptor interacting protein 3 downstream component of TNFinduced necrosis. Proc Natl Acad Sci USA. 2012;109:5322-7.

62. Dondelinger Y, Jouan-Lanhouet S, Divert T, Theatre E, Bertin J, Gough PJ, et al. NFkappaB-Independent role of IKKalpha/IKKbeta in preventing RIPK1 kinasedependent apoptotic and necroptotic cell death during TNF Signaling. Mol Cell. 2015;60:63-76.

63. Vanlangenakker N, Vanden Berghe $T$, Bogaert $\mathrm{P}$, Laukens $\mathrm{B}$, Zobel K, Deshayes $\mathrm{K}$, et al. CIAP1 and TAK1 protect cells from TNF-induced necrosis by preventing RIP1/RIP3-dependent reactive oxygen species production. Cell Death Differ. 2011;18:656-65.

64. Dziedzic SA, Su Z, Jean Barrett V, Najafov A, Mookhtiar AK, Amin P, et al. ABIN-1 regulates RIPK1 activation by linking Met1 ubiquitylation with Lys63 deubiquitylation in TNF-RSC. Nat Cell Biol. 2018;20:58-68.

65. Feoktistova M, Geserick P, Kellert B, Dimitrova DP, Langlais C, Hupe M, et al. CIAPs block Ripoptosome formation, a RIP1/caspase-8 containing intracellular cell death complex differentially regulated by cFLIP isoforms. Mol Cell. 2011;43:449-63.

66. He S, Liang Y, Shao F, Wang X. Toll-like receptors activate programmed necrosis in macrophages through a receptor-interacting kinase-3-mediated pathway. Proc Natl Acad Sci USA. 2011;108:20054-9.

67. Rickard JA, O'Donnell JA, Evans JM, Lalaoui N, Poh AR, Rogers T, et al. RIPK 1 regulates RIPK3-MLKL-driven systemic inflammation and emergency hematopoiesis. Cell. 2014;157:1175-88.

68. Dillon CP, Weinlich R, Rodriguez DA, Cripps JG, Quarato G, Gurung P, et al. RIPK1 blocks early postnatal lethality mediated by caspase-8 and RIPK3. Cell. 2014;157:1189-202.

69. Heger K, Wickliffe KE, Ndoja A, Zhang J, Murthy A, Dugger DL, et al. OTULIN limits cell death and inflammation by deubiquitinating LUBAC. Nature. 2018;559:120-4.

70. Lafont E, Draber P, Rieser E, Reichert M, Kupka S, de Miguel D, et al. TBK1 and IKKepsilon prevent TNF-induced cell death by RIPK1 phosphorylation. Nat Cell Biol. 2018;20:1389-99.

71. Hughes MA, Harper N, Butterworth M, Cain K, Cohen GM, MacFarlane M. Reconstitution of the death-inducing signaling complex reveals a substrate switch that determines CD95-mediated death or survival. Mol Cell. 2009;35:265-79.

72. Chang DW, Xing Z, Capacio VL, Peter ME, Yang X. Interdimer processing mechanism of procaspase-8 activation. EMBO J. 2003;22:4132-42.

73. Brumatti G, Ma C, Lalaoui N, Nguyen NY, Navarro M, Tanzer MC, et al. The caspase-8 inhibitor emricasan combines with the SMAC mimetic birinapant to induce necroptosis and treat acute myeloid leukemia. Sci Transl Med. 2016;8:339ra369.

74. Zhang X, Zhang H, Xu C, Li X, Li M, Wu X, et al. Ubiquitination of RIPK1 suppresses programmed cell death by regulating RIPK1 kinase activation during embryogenesis. Nat Commun. 2019;10:4158.

75. Zhang $X$, Fan $C$, Zhang $H$, Zhao $Q$, Liu $Y, X u C$, et al. MLKL and FADD are critical for suppressing progressive lymphoproliferative disease and activating the NLRP3 inflammasome. Cell Rep. 2016;16:3247-59.

\section{ACKNOWLEDGEMENTS}

We thank Dr. Xiaodong Wang (National Institute of Biological Sciences, Beijing, China) for providing Ripk3 ${ }^{-1-}$ mice. The authors thank Zhonghui Weng (Shanghai Institute of Nutrition and Health, Chinese Academy of Sciences) for animal studies and Lin Qiu (Shanghai Institute of Nutrition and Health, Chinese Academy of Sciences) for flow cytometry technical support.

\section{AUTHOR CONTRIBUTIONS}

$\mathrm{XML}$ and $\mathrm{HBZ}$ designed the study and performed data analyses. $\mathrm{XML}$ and $\mathrm{LF}$ carried out most of experiments with assistance from XXZ, ML, LXW, JLL, XHW, YJO, MYX, YZ, JSD and XZW. HWZ and QZ assisted with cell death analyses in vitro and Fas-induced apoptosis in vivo, XXW helped to perform mouse breeding. JBL, YL and YWZ provided essential reagents and intellectual input. HBZ and XML coordinated the project and wrote the paper with the help from LF. HBZ supervised the project.

\section{FUNDING}

This work was supported by grants from the Strategic Priority Research Program of Chinese Academy of Sciences (Grant No. XDA26040306), the National Natural Science Foundation of China $(31970688,31771537,82001684,81871101)$ and the National Key Research and Development Program of China (2018YFC1200201, 2016YFC1304900). We also thank support from Shanghai Frontiers Science Center of Cellular Homeostasis and Human Diseases.

\section{COMPETING INTERESTS}

The authors declare no competing interests.

\section{ETHICS APPROVAL}

Our studies did not include human participates, human data or human tissues. Animal experiments were conducted in accordance with the guidelines of the Institutional Animal Care and Use Committee of the Institute of Nutrition and Health, Shanghai Institutes for Biological Sciences, University of Chinese Academy of Sciences.

\section{ADDITIONAL INFORMATION}

Supplementary information The online version contains supplementary material available at https://doi.org/10.1038/s41418-022-00938-9.

Correspondence and requests for materials should be addressed to Haibing Zhang.

Reprints and permission information is available at http://www.nature.com/reprints

Publisher's note Springer Nature remains neutral with regard to jurisdictional claims in published maps and institutional affiliations.

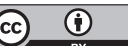

Open Access This article is licensed under a Creative Commons Attribution 4.0 International License, which permits use, sharing, adaptation, distribution and reproduction in any medium or format, as long as you give appropriate credit to the original author(s) and the source, provide a link to the Creative Commons license, and indicate if changes were made. The images or other third party material in this article are included in the article's Creative Commons license, unless indicated otherwise in a credit line to the material. If material is not included in the article's Creative Commons license and your intended use is not permitted by statutory regulation or exceeds the permitted use, you will need to obtain permission directly from the copyright holder. To view a copy of this license, visit http://creativecommons. org/licenses/by/4.0/.

(c) The Author(s), under exclusive licence to ADMC Associazione Differenziamento e Morte Cellulare 2022 